\title{
Cooperação para inovar no Brasil: diferenças segundo a intensidade tecnológica e a origem do capital das empresas
}

\author{
Milene Simone Tessarin ${ }^{1}$ \\ Wilson Suzigan ${ }^{2}$ \\ Joaquim José Martins Guilhoto ${ }^{3}$
}

\section{Resumo}

Este artigo analisa o esforço inovativo das empresas manufatureiras no Brasil com o objetivo de comparar as empresas que cooperaram para inovar com as que inovaram sem cooperação, segmentando-as por categorias de intensidade tecnológica e por origem do capital controlador. A pergunta a ser respondida é se a cooperação é um fator de diferenciação no esforço inovativo das empresas segundo categorias de intensidade tecnológica e origem do capital. Para isso foram utilizados dados inéditos provenientes de uma tabulação especial da Pesquisa de Inovação (Pintec/IBGE). Os resultados mostram que a cooperação é decisiva para diferenciar os esforços inovativos, independentemente da categoria de intensidade tecnológica. A origem do capital, porém, não influi na diferenciação do esforço inovativo. A cooperação foi essencialmente feita com clientes, fornecedores, e outra empresa do grupo no exterior para empresas estrangeiras. Esse resultado contrasta com a literatura, que enfatiza a cooperação com universidades e institutos de pesquisa. Conclui-se que cooperar para inovar é positivo para o desempenho inovativo das empresas, e que estimular empresas a cooperar pode aumentar a capacidade de inovar das empresas manufatureiras no Brasil.

\section{Palavras-Chave}

Cooperação. Inovação. Tecnologia. Empresa. Brasil.

1 Pós-doutoranda - DST/NRF South African Research Chair (SARChI) in Industrial Development University of Johannesburg - End.: Sarchi in Industrial Development. 31 Henley Road, Auckland Park - Johannesburg, 2092 - África do Sul - E-mail: milenetessarin@alumni.usp.br. ORCID: https://orcid.org/0000-0003-2922-8335.

2 Professor Colaborador - Universidade Estadual de Campinas - Instituto de Geociências End.: Rua Carlos Gomes, 250 - Cidade Universitária - Campinas - SP - Brasil - CEP: 13083-855. E-mail: wsuzigan@unicamp.br. - ORCID: https://orcid.org/0000-0002-2193-4756.

3 Organização para Cooperação e Desenvolvimento Econômico (OCDE) e Universidade de São Paulo. End.: 2 Rue André-Pascal. 75775, Paris CEDEX 16 - França - E-mail: joaquim.guilhoto@oecd.org. ORCID: https://orcid.org/0000-0002-7098-1209. O conteúdo desta publicação expressa a visão deste autor e não necessariamente representa a visão da OCDE ou dos seus países membros. Recebido: 23/04/2019. Aceito: 20/08/2020

Editor responsável: Dante Mendes Aldrighi

(c) (i) (9) Esta obra está licenciada com uma Licença Creative Commons Atribuição-Não Comercial 4.0 Internacional. 


\begin{abstract}
This paper analyses the innovation performance of manufacturing firms in Brazil with the objective of comparing innovating firms that cooperate with those that do not cooperate, according to firms' technological intensity and origin of capital. The research question is whether cooperation affects a differentiation in the innovation performance of firms according to categories of technological intensity and origin of capital. Evidences were provided by a compilation of original data from Brazilian Innovation Survey (Pintec/IBGE). The results show that cooperation is decisive for the differentiation of firms' innovation performance, independently of categories of technological intensity. The origin of capital, in turn, has no influence on the differentiation of firms' innovation performance. Cooperation occurred mainly with clients, suppliers, and with another firm of the same business group in the case of multinationals. This result contrasts with the literature which emphasizes cooperation with universities and research institutes. The paper concludes that cooperation to innovate is positive for firms' innovation performance, and that to stimulate firm cooperation may increase the innovativeness of Brazilian manufacturing firms.
\end{abstract}

\title{
Keywords
}

Cooperation. Innovation. Technology. Firm. Brazil.

\section{JEL Classification}

O32. L25. L60. O54.

\section{Introdução ${ }^{1}$}

A interação ou cooperação para inovar é um dos elementos que fomentam o desenvolvimento tecnológico do setor produtivo. Relata-se que empresas que realizam cooperação para inovar apresentam maior capacidade inovativa e acumulação de conhecimento, e conseguem aproveitar melhor o conhecimento disponível fora da empresa. Através da cooperação, as partes envolvidas podem gerenciar melhor seus ativos, acessar recursos produtivos e técnicos distantes ou indisponíveis, trocar conhecimentos e tecnologias com outros especialistas e capacitar-se para processos mais eficientes (Klevorick et al. 1995).

1 Os autores gostariam de agradecer os comentários recebidos dos pareceristas anônimos e do editor da Estudos Econômicos, que contribuíram para uma melhoria na qualidade do artigo, tornando-o mais claro e consistente. Também agradecemos à Fipe pelo apoio financeiro e aos membros do Núcleo de Economia Regional e Urbana da USP (NEREUS-USP) pelas discussões. O presente trabalho foi realizado com apoio da Coordenação de Aperfeiçoamento de Pessoal de Nível Superior (CAPES) Código de Financiamento 001. 
Existem diversos parceiros da cooperação, incluindo relações verticais (dentro da cadeia produtiva) ou agentes externos (como institutos de pesquisa, universidades ou redes de informação) (Araújo, 2005; Zucolo \& Cassiolato 2012). No Brasil, há uma vasta literatura que aborda a parceria entre empresas e universidades ou institutos de pesquisa (Albuquerque, Silva \& Póvoa 2005; Cassiolato, Britto \& Vargas 2005; Suzigan et al., 2009; Fernandes et al., 2010). No entanto, esse não é o tipo de parceria mais frequentemente realizado no Brasil. As parcerias com universidades requerem que a empresa esteja capacitada para absorver e internalizar conhecimentos originados em pesquisas de avançado nível, por isso não são corriqueiras e se limitam a um determinado grupo de empresas.

A elevada presença de empresas multinacionais estrangeiras é uma característica marcante da indústria de transformação brasileira (Queiroz \& Carvalho 2005). Desde a década de 1950, filiais dessas companhias se instalaram no país e lideraram o desenvolvimento produtivo e tecnológico em diversos setores relevantes (Queiroz \& Carvalho 2005; Cassiolato, Matos \& Lastres 2014). Atualmente, tais filiais dividem o protagonismo em termos produtivo e inovador em vários setores manufatureiros, com as empresas de capital nacional. Conforme é amplamente argumentado pela literatura, as estratégias de atuação das filiais de uma multinacional são dependentes da matriz, que determina como irá distribuir as atividades produtivas e tecnológicas. Por isso, a origem do capital pode desempenhar diferentes efeitos sobre as atividades inovativas do país hospedeiro.

Outro fator que pode influenciar a intensidade e o tipo de atividade inovativa realizado no país refere-se ao setor produtivo em que a empresa atua. Há oportunidades e riscos tecnológicos distintos entre os setores manufatureiros (Breschi \& Malerba 1997). Também existem graus distintos de codificação das tecnologias (Furtado \& Carvalho 2005), o que influencia as atividades inovativas desenvolvidas por cada setor.

Este trabalho tem como preocupação central responder a seguinte pergunta: a cooperação é um fator de diferenciação no esforço inovativo das empresas localizadas no Brasil? Para tanto, foram analisados na literatura todos os parceiros utilizados por empresas de modo a entender se, além da cooperação com universidades e institutos de pesquisa, a cooperação com outros agentes é importante para a inovação. Além disso, as empresas também foram segmentadas por origem do capital e categoria de intensidade tecnológica da OCDE (Hatzichronoglou 1997) para avaliar se há 
diferenças no esforço inovativo quando se considera o capital controlador e a intensidade tecnológica. A análise foi realizada com base no esforço e nas características das empresas que implementaram inovações no Brasil.

Os dados provêm de uma tabulação especial inédita da Pesquisa de Inovação Tecnológica (Pintec), elaborada pelo Instituto Brasileiro de Geografia e Estatística (IBGE), para o intervalo de uma década, abrangendo os períodos de 2001-2003 e 2012-2014. Este estudo busca contribuir ao comparar os resultados de empresas inovadoras que cooperam em contraposição às que não cooperam, segundo categorias de intensidade tecnológica, comparação essa raramente presente na literatura. Como contribuição secundária, foram qualificadas as diferenças no perfil de empresas agrupadas pelo capital controlador. Por fim, o presente trabalho destaca-se por retratar todas as opções de parceiros na cooperação para inovar, ampliando a abordagem para além das parcerias com universidades e institutos de pesquisa.

Após esta introdução, a seção 2 sintetiza o referencial teórico sobre o papel da cooperação no contexto inovativo e a influência de empresas multinacionais na inovação dos países hospedeiros. A seção 3 apresenta a base de dados e procedimentos metodológicos. A seção 4 exibe os resultados que mostram o perfil das empresas inovadoras no Brasil, os sete parceiros utilizados na cooperação, as 14 fontes de informação consultadas para inovar e uma síntese dos esforços inovativos bastante detalhada para cada um dos grupos de empresas analisados. A seção 5 consiste na conclusão.

\section{Referencial teórico}

A seguir serão apresentados os argumentos teóricos que permeiam o artigo. Primeiro, discute-se como a cooperação beneficia a capacidade inovativa e porque é importante considerar vários tipos de parceiros para inovar. $\mathrm{Na}$ sequência, debatem-se os argumentos sobre a influência de empresas de capital estrangeiro na atividade inovativa dos países em que suas filiais atuam. Pretende-se estabelecer uma conexão para verificar se há variações no desempenho inovativo de empresas que cooperam para inovar quando há diferenças na origem do capital. 


\subsection{A importância da cooperação para a inovação empresarial}

$\mathrm{Na}$ atual sociedade do conhecimento (OECD 2017), os novos produtos são cada vez mais sistêmicos e multifuncionais. Uma empresa que busca a inovação não atua em apenas um campo do conhecimento ou restringe sua área de pesquisa aos desenvolvimentos realizados em seu próprio laboratório de pesquisa e desenvolvimento (P\&D). Há diversas outras fontes de informações e parceiros que as empresas podem consultar para otimizar seu tempo, absorver conhecimentos que não faziam parte de seu portfólio, compartilhar custos, solucionar problemas incontornáveis, entre outros motivos. Entretanto, essa não é uma tarefa simples. A difusão e absorção bem-sucedida de novas tecnologias requerem esforços de adaptação e conhecimento acumulado por parte das empresas, uma vez que o conhecimento não é um bem público facilmente transferível.

Alguns estudos mostram que empresas que realizam cooperação para inovar apresentam uma capacidade inovativa e de acumulação de conhecimento maior e conseguem aproveitar melhor o conhecimento disponível fora da firma. Um estudo sobre empresas inovadoras portuguesas (Faria, Lima e Santos 2010) verificou que aquelas que consideraram a cooperação como estratégia de alta relevância possuem mais empregados, esses com maior proporção com ensino superior e que valorizam mais a gestão dos spillovers de conhecimento. Essas empresas também tinham como característica comum fazer parte de um grupo e desenvolverem atividades de P\&D.

Outro estudo, que analisou os países europeus (Abramovsky et al. 2009), comprovou que empresas inovadoras que cooperaram possuem maior capacidade de apropriar-se de conhecimentos gerados externamente, e apresentam níveis de desempenho globais mais altos. Além disso, também foi encontrado que empresas que cooperam tendem a lançar inovações para o mercado, e não apenas para a firma (Tether 2002), ou seja, a abrangência da inovação é maior.

Já no cenário brasileiro, nota-se que, em geral, a cooperação para inovar é uma estratégia adotada por um grupo seleto de empresas. O estudo de Cassiolato, Britto, e Vargas (2005) mostrou que, entre 1998 e 2000, apenas $11 \%$ do total de empresas inovadoras cooperaram. No entanto, as relações firmadas foram relevantes, especialmente para empresas que inovam e diferenciam produtos. Muitos estudos brasileiros se concentram na análise da cooperação entre empresas e universidades ou institutos de pesquisa. Por exemplo, Pinho (2011) verificou a proporção de empresas que 
consideram universidades como fonte de informação para inovar. O autor conclui que o percentual, embora não elevado, é maior no Brasil do que na média dos países da União Europeia $(6,8 \%$ e 4,3\% em relação ao total, respectivamente). Já na Hungria, 11,6\% das empresas consideraram as universidades como relevantes parceiros para inovar, comparativamente a 5,8\% na Alemanha, 2,5\% na França e 3,0\% na Itália (Pinho 2011). Albuquerque, Silva, e Póvoa (2005) identificaram, a partir de uma pesquisa amostral com cerca de 320 empresas, que empresas que investem em P\&D utilizam mais as universidades como fontes de informação em suas atividades inovativas, principalmente aquelas que desenvolvem $P \& D$ interno e externo. Além disso, mesmo empresas que não fazem $P \& D$ nem adquirem $P \& D$ externa também consideram a cooperação com universidades como relevante porque, segundo os autores, a universidade é utilizada como um substituto do investimento interno diante de uma restrição de recursos financeiros.

Há também um grupo de pesquisadores que analisou a cooperação para inovar no Brasil do ponto de vista das universidades. Por meio da análise do Diretório de Grupos de Pesquisa do Conselho Nacional de Desenvolvimento Científico e Tecnológico (CNPq), Rapini (2007) notou que os fluxos de conhecimentos e serviços oriundos dos grupos de pesquisa são utilizados pelas empresas principalmente em atividades rotineiras. Suzigan et al. (2009) conseguiram identificar que, das possíveis formas de relacionamento entre universidades e empresas, a pesquisa acadêmica tem grande influência para a criação e difusão de novos conhecimentos para as empresas. Além desse impacto, Fernandes et al. (2010) observaram que todos os lados da cooperação obtêm benefícios: as universidades têm ganhos intelectuais e econômicos, os institutos de pesquisa têm benefícios intelectuais, enquanto para as empresas há melhores resultados inovativos e produtivos.

Contudo, além das universidades há outros tipos de parceiros que as empresas podem contatar para inovar. Há alguns estudos que não tinham como preocupação central pesquisar a cooperação, mas mostraram que outras formas de parceria são empregadas pelas empresas inovadoras no Brasil. Zucoloto e Cassiolato (2012) apontam que o Brasil segue o perfil de outros países, cujas parcerias para inovar são fruto das relações de empresas com fornecedores e clientes, e são mais significativos do que relacionamentos horizontais entre concorrentes. Araújo (2005) identificou padrão similar de parcerias, porém com uma diferença em relação às empresas multinacionais que inovam e diferenciam produtos, as quais também cooperam com outra empresa do seu grupo para inovar. Bastos 
e Britto (2017) identificaram que empresas nacionais colaboraram menos com universidades, centros de pesquisa e de capacitação técnica quando comparadas com empresas de controle estrangeiro no período de 2003 a 2011 (de acordo com a Pintec). Porém, a taxa de participação das nacionais no grupo colaborativo cresceu mais rapidamente, notadamente entre empresas com até 500 empregados.

Dado que esse tema ainda é pouco aprofundado pela literatura, nos preocuparemos em analisar a cooperação para inovar considerando todos os tipos de parceria que podem ser realizados, apresentando o esforço empreendido pelas empresas que cooperaram e não cooperaram para inovar para determinar se este é um fator importante para distinguir o desempenho inovativo das empresas.

Vale frisar que a cooperação envolve um componente social - e não apenas relações mercantis (Powell 1990). A dimensão social das redes impacta de modo crucial sua operacionalização, definindo os tipos de relacionamento de acordo com as posições dos atores mais privilegiados. Segundo Britto (2013), redes organizacionais podem explicar o conjunto de relações estabelecidas e o padrão de conduta dos diversos atores envolvidos. Nesse contexto, as informações são recursos intangíveis que se somam aos tradicionais recursos tangíveis (insumos e produtos) (Britto 2002). Assim, a difusão do conhecimento pode ser facilitada ou dificultada em decorrência da estrutura da rede em termos organizacionais, da força de alguns atores em oposição à dependência de outros, e do fluxo de informações (Granovetter 1973). O pressuposto básico é que uma parte dos envolvidos depende de recursos controlados por outra parte, mas no fim há ganhos a serem obtidos com o agrupamento de recursos (Powell 1990), fato que acaba estimulando a formação e manutenção de parcerias.

\subsection{A influência das empresas multinacionais no desenvolvimento tecnológico}

As maiores empresas inovadoras do mundo são grandes multinacionais ${ }^{2}$ que detêm um estoque de conhecimento acumulado ao longo de gerações e, por isso, possuem papel importante na execução e internacionalização das atividades inovativas. A estratégia inovativa traçada por empresas mul-

2 Empregaremos os termos empresa multinacional, empresa de capital estrangeiro ou empresas transnacionais com o mesmo sentido. 
tinacionais impacta o desempenho dos países que hospedam unidades produtivas e de $P \& D$, uma vez que pode complementar ou limitar o potencial inovativo local, conforme será abordado a seguir.

Sem dúvida, o avanço dos sistemas de informação e comunicação e a redução de barreiras logísticas contribuíram para o deslocamento (parcial) das atividades produtivas, edificando assim as cadeias globais de valor (Gereffi, Humphrey \& Sturgeon 2005). Países em desenvolvimento bem-sucedidos nas cadeias globais passaram também a atrair unidades de P\&D das multinacionais estrangeiras (Gereffi, Humphrey \& Sturgeon 2005). Entre os motivos que levam as empresas a internacionalizarem suas atividades de pesquisa, Gomes (2003) apontou que há um conjunto de forças favoráveis e contrárias. Como forças centrífugas (ou favoráveis à descentralização), o autor se amparou em Pearce (1999) e elencou: adaptação, em que a empresa visa desenvolver produtos novos para o segmento regional da subsidiária; interdependência, quando a subsidiária segue os programas de desenvolvimento de tecnologias já existentes na matriz; e o patrimônio tecnológico do país, que pondera o estoque de conhecimento acumulado com a qualidade da capacitação científica local. Já entre as forças centrípetas (ou desfavoráveis à distribuição geográfica), Gomes (2003) indicou a existência de economias de escala na execução da $\mathrm{P} \& \mathrm{D}$; as economias de integração e aglomeração, que facilitam os transbordamentos de informação; o fato de a inovação ser destinada a uma demanda local; e problemas de controle e coordenação, que resultam em perda de foco.

A despeito das forças centrípetas, a organização das atividades empresariais em cadeias globais de valor vem transformando a alocação espacial da atividade econômica e inovativa. Como consequência, o perfil da atividade inovativa nos países hospedeiros pode variar. Alguns autores encontraram uma relação positiva entre a propriedade estrangeira e a atividade inovativa em países receptores. Guadalupe, Kuzmina, e Thomas (2012) mostraram que empresas estrangeiras podem aumentar a taxa de inovação do país hospedeiro por meio da implantação de plantas industriais modernas e adoção de melhores práticas organizacionais. Para Falk (2008), a transferência de tecnologias desenvolvidas no país-sede para o país hospedeiro exige o domínio de conhecimentos específicos, conduz a adaptação na linha de produção e atualização tecnológica, demanda recursos humanos qualificados e, por vezes, o desenvolvimento de parceiros de pesquisa. Como as subsidiárias não conseguem se apropriar integralmente dos transbordamentos gerados por suas atividades, há um repasse não intencional 
e parcial para as empresas domésticas através de efeitos de demonstração (via imitação), competição (ao impulsionar empresas domésticas a atualizar suas tecnologias) e treinamento de mão de obra (Zucoloto \& Cassiolato 2012). No mesmo sentido, Araújo (2005) aponta haver transbordamentos a partir das multinacionais via transferência de pessoal capacitado que traria conhecimentos essenciais para a realização de $\mathrm{P} \& \mathrm{D}$ e, segundo, pelo efeito competição entre empresas nacionais e estrangeiras que estão próximas em termos de capacidade tecnológica.

Numa visão oposta, alguns autores argumentam que o efeito da propriedade estrangeira sobre a atividade inovativa dos países hospedeiros pode ser nocivo. Zucoloto e Cassiolato (2012), ao analisarem dados de grandes empresas localizadas no Brasil, sugerem que, a um primeiro olhar, há um efeito dúbio. No agregado, as empresas multinacionais parecem incrementar o esforço inovativo brasileiro, uma vez que possuem um percentual de investimento em $\mathrm{P} \& \mathrm{D}$ em relação às vendas mais elevado que as nacionais, no entanto, setorialmente esse cenário sofre alterações. Entre 18 setores observados em 2005, em 12 o esforço realizado por empresas nacionais foi superior. Os autores ponderaram que isso se deve, em parte, a uma concentração setorial significativa dos esforços inovativos das filiais (com foco no setor automotivo) que não estimula transbordamentos tecnológicos dentro do país de forma ampla. Outros autores foram mais incisivos e argumentaram que quando a atividade inovativa desenvolvida no país hospedeiro é fraca, limita-se o potencial de desenvolvimento tecnológico e criativo do país (Rama 2008). A disponibilidade de tecnologia externa desenvolvida na matriz ou em outra filial pode desencorajar ou substituir o investimento em pesquisa no país receptor e, consequentemente, não há internalização de novos conhecimentos (Veugelers 1997). Para Furtado e Carvalho (2005), as diferenças estruturais entre países desenvolvidos e em desenvolvimento tendem a inibir o esforço inovativo em decorrência da presença de multinacionais, dado que as subsidiárias têm acesso facilitado ao conteúdo tecnológico desenvolvido por sua matriz. Zucoloto e Toneto Jr. (2005) analisaram os setores manufatureiros no Brasil através da Pintec e da Pesquisa Industrial Anual do IBGE e, ao compararem com dados de outros países disponibilizados pela OCDE, encontraram que quanto maior a participação do capital estrangeiro em uma indústria, menor o esforço tecnológico relativo realizado por ela. Segundo eles, as empresas estrangeiras concentram suas atividades nos países hospedeiros em produtos menos sofisticados e por isso a $\mathrm{P} \& \mathrm{D}$ realizada nesses locais não tem a mesma intensidade observada nos países desenvolvidos. 
Dados de empresas norte-americanas ajudam a elucidar a diferença na estratégia inovativa de empresas multinacionais. Os EUA são o líder mundial em investimento em $P \& D$ e suas multinacionais participam de várias etapas das cadeias globais de valor. A Tabela 1 exibe o percentual médio, entre 2009 e 2015, dos dispêndios em P\&D em relação às vendas efetuados pelas empresas dos EUA, distinguindo-as a partir do local de atuação.

Tabela 1 - Investimentos em P\&D (em relação às vendas) de empresas dos EUA, por local de atuação, média de 2009 a 2015, em \%

\begin{tabular}{lccc}
\hline Setor de atividade e & \multicolumn{3}{c}{ Local de atuação } \\
\cline { 2 - 4 } categorias tecnológicas & Dentro dos EUA & Fora dos EUA & Apenas no Brasil \\
\hline Alimentos & 0,52 & 0,26 & 0,11 \\
\hline Bebidas e fumo & 0,36 & 0,09 & - \\
\hline Têxteis, vestuário e produtos de couro & 0,74 & 0,54 & - \\
\hline Produtos de madeira & 0,76 & 0,20 & - \\
\hline Papel e celulose & 1,63 & 0,25 & - \\
\hline Impressão e atividades de apoio & 0,31 & 0,16 & - \\
\hline Coque e derivados & 0,32 & 0,00 & 1,01 \\
\hline Químicos exc. Farmacêuticos & 2,78 & 0,61 & - \\
\hline Produtos farmacêuticos & 15,06 & 3,60 & - \\
\hline Plástico e borracha & 1,30 & 0,81 & 0,22 \\
\hline Produtos minerais não metálicos & 1,22 & 0,40 & 0,70 \\
\hline Metais básicos & 0,43 & 0,25 & 1,06 \\
\hline Produtos fabricados de metal & 1,34 & 0,54 & 0,03 \\
\hline Máquinas e equipamentos & 3,55 & 1,32 & 2,16 \\
\hline Informática e eletrônicos & 9,19 & 1,66 & - \\
\hline Máquinas e materiais elétricos & 3,60 & 1,24 & 0,11 \\
\hline Veículos a motor, partes e peças & 3,04 & 1,93 & 0,22 \\
\hline Outros equipamentos de transporte & 6,42 & 2,42 & 1,12 \\
\hline Móveis & 1,50 & 0,52 & 1,06 \\
\hline Baixa tecnologia & 0,67 & 0,23 & $\mathbf{0 , 9 0}$ \\
Média-baixa tecnologia & 0,47 & 0,27 & \\
Média-alta tecnologia & 4,05 & 1,37 & 2,28 \\
Alta tecnologia & 11,51 & $\mathbf{1 , 2 4}$ & \\
\hline Indústria de transformação & $\mathbf{3 , 8 3}$ & & \\
\hline
\end{tabular}

Fonte: U.S. Bureau of Economic Analysis. Cálculos e elaboração dos autores.

É evidente que empresas estadunidenses ${ }^{3}$ da indústria de transformação realizaram investimentos em $\mathrm{P} \& \mathrm{D}$ dentro dos EUA maiores que o volume investido por subsidiárias instaladas fora dos EUA (especialmente nos setores

3 De acordo com o U.S. Bureau of Economic Analysis, são consideradas empresas estadunidenses quando o capital majoritário pertence a residentes dos EUA. O local de atuação consiste na unidade territorial em que a filial da empresa está realizando suas operações, que pode ser doméstico ou estrangeiro. 
de alta tecnologia). No caso da indústria de transformação, essa diferença é três vezes maior e se replica para todos os setores manufatureiros e por categorias de intensidade tecnológica, como se nota na Tabela 1. Em geral, inicialmente as empresas multinacionais estabelecem seu centro de P\&D no país-sede e estrategicamente distribuem outros centros secundários de pesquisa motivadas pelo acesso a ativos de interesse localizados no exterior (tanto ativos físicos como conhecimento e tecnologia) ou quando encontram algum tipo de vantagem tecnológica, gerencial ou organizacional sobre seus concorrentes em outros países (Dunning 1994).

As diferenças setoriais exibidas na Tabela 1 são explicadas, por um lado, pelas oportunidades tecnológicas de cada setor, que tendem a ser maiores nos setores da vanguarda tecnológica devido a maiores possibilidades de aplicação da tecnologia em novos produtos (Breschi e Malerba 1997) e, por outro, pelas diferenças existentes entre países mais avançados e países em desenvolvimento (Furtado e Carvalho 2005), que são impactadas pelos requisitos de políticas locais, o tamanho do mercado doméstico e o conteúdo tácito da tecnologia, por exemplo.

No Brasil, as filiais estadunidenses investem em $\mathrm{P} \& \mathrm{D}$ (em relação às vendas) percentual ainda menor do que no conjunto dos países hospedeiros, em todas as categorias de intensidade tecnológica (Tabela 1). Mesmo nos setores automobilístico e de outros equipamentos de transportes, nos quais há grande presença de filiais estadunidenses atuando no Brasil há várias décadas, o percentual das vendas investido em P\&D no agregado do setor é similar ao investido em outros países hospedeiros e muito inferior ao investido nos EUA. ${ }^{4}$ Pesquisas mostraram que os recursos destinados a P\&D por filiais de empresas multinacionais no Brasil são bastante concentrados, sendo o setor automotivo o mais significativo deles (Zucoloto e Cassiolato 2012; Consoni 2004). A única exceção está no setor químico, salvo o farmacêutico, em que o Brasil recebe $1,01 \%$ dos dispêndios em $\mathrm{P} \& \mathrm{D}$ em relação às vendas das empresas estadunidenses aqui instaladas, frente a $0,61 \%$ do que é feito fora dos EUA (mas ainda abaixo do volume de 2,78\% realizado no próprio país).

4 No agregado do setor de equipamentos de transportes (inclui veículos e outros equipamentos de transportes), as filiais estadunidenses investiram no Brasil 2,16\% das vendas em P\&D; nos demais países hospedeiros 1,96\% e nos Estados Unidos 4,68\%. 


\section{Procedimentos metodológicos}

\subsection{Dados}

Os dados utilizados neste artigo são inéditos e provêm da Pesquisa de Inovação Tecnológica (Pintec) do IBGE. A Pintec segue as definições sobre atividades inovativas do Manual de Oslo, o qual é adotado nos surveys de inovação nos países da OCDE (OECD 2017). Foram utilizadas as versões da Pintec 2003 e 2014, que englobam o período 2001 a 2003 (IBGE 2005) e 2012-2014 (IBGE 2016), ${ }^{5}$ respectivamente. Com isso, buscou-se captar modificações de caráter estrutural e que são menos influenciadas pelo ciclo de negócios. Ressalta-se que a última Pintec, ao captar o período de 2012-2014, praticamente não foi influenciada pela crise político-econômica que se agravou em 2015 e 2016. Todos os dados monetários apresentados foram deflacionados para valores de 2016 pelo deflator implícito do PIB calculado a partir das contas nacionais trimestrais do IBGE.

No total, a Pintec identificou, aproximadamente, 28 mil empresas inovadoras da indústria de transformação para o triênio 2001-2003 e 42 mil no triênio 2012-2014. Em ambos os períodos, o grupo de empresas inovadoras representou $70 \%$ da receita líquida de vendas de toda a indústria de transformação brasileira.

\subsection{Estratégia de seleção}

Foi solicitada ao IBGE uma tabulação especial de todas as empresas da indústria de transformação segmentadas em quatro grupos: empresas estrangeiras que inovaram com relações de cooperação; empresas estrangeiras que inovaram sem relação de cooperação; empresas nacionais que inovaram com relações de cooperação; e empresas nacionais que inovaram sem relação de cooperação. ${ }^{6}$ Essa forma de analisar as informações permitiu uma abordagem distinta da observada nos trabalhos prévios.

5 A primeira edição da Pintec ocorreu em 2000. Porém, optou-se por utilizar dados com início em 2003 pelo fato de as empresas estarem mais familiarizadas com o entendimento e a aplicação do conceito de inovação.

6 Optou-se por não selecionar empresas de capital misto porque o seu dispêndio total com inovação foi pequeno. Em 2003 havia 250 empresas de capital misto (0,9\% do total de empresas inovadoras) e $440(1,1 \%)$ em 2014. Elas realizaram 1,1\% do dispêndio total com inovação em ambos os períodos. 
A cooperação para inovação é definida como "a participação ativa da empresa em projetos conjuntos de $\mathrm{P} \& \mathrm{D}$ e outros projetos de inovação com outra organização (empresa ou instituição), o que não necessariamente implica que as partes envolvidas obtenham benefícios comerciais imediatos" (IBGE 2004, p. 97). Contratar produtos e serviços de outra organização sem participar ativamente do desenvolvimento não é considerado cooperação, mas uma atividade comercial. A investigação sobre a cooperação englobará todos os parceiros utilizados para inovar no Brasil.

A origem do capital empregado na Pintec define que o capital controlador é nacional (estrangeiro) quando está sob titularidade direta ou indireta de pessoas físicas ou jurídicas residentes e domiciliadas no país (fora do país) (IBGE 2004, p. 85).

Por fim, dado que os setores produtivos contribuem de formas diferentes para o desenvolvimento tecnológico do país devido às oportunidades tecnológicas distintas, também foi solicitada a desagregação da indústria de transformação nas quatro categorias de intensidade tecnológica da OCDE: baixa, média-baixa, média-alta e alta tecnologia. ${ }^{7}$ Utilizou-se a Classificação Nacional de Atividades Econômicas (CNAE) para alocar os respectivos setores por categorias de intensidade tecnológica. ${ }^{8} \mathrm{~A}$ combinação das informações resultou em dados que não estão disponíveis publicamente, e por isso garantem uma abordagem original sobre o perfil da inovação neste artigo.

\section{Resultados}

No Brasil, de acordo com os dados da Pintec, 33 em cada 100 empresas inovaram no período de 2001 a 2003, enquanto, entre 2012 e 2014, 36 em cada 100 empresas realizaram alguma inovação. No comparativo internacional, a taxa de inovação brasileira é ligeiramente inferior a dos 15 países

7 Neste artigo foi adotada a versão da classificação da OCDE elaborada por Hatzichronoglou (1997). Para facilitar a interpretação, iremos empregar os termos "empresas de setores" de uma dada categoria tecnológica e "empresas" dessa categoria tecnológica como sinônimos.

8 A Pintec 2003 utiliza a classificação setorial CNAE versão 1.0 e a Pintec 2014 emprega a versão 2.0. Não foi possível desagregar o setor "outros equipamentos de transporte" (que inclui embarcações, veículos ferroviários, aviões e veículos militares de combate), o qual foi totalmente alocado na categoria de média-alta tecnologia para os cálculos realizados em ambas as edições da Pintec. 
que formaram inicialmente a União Europeia (Koeller 2018). Apesar de as empresas inovadoras representarem um terço do número de empresas, elas detêm mais de dois terços da receita líquida de vendas. Logo, as empresas inovadoras possuem maior market share em comparação com as empresas não inovadoras. No entanto, existe um grupo específico de empresas com maior esforço inovativo e que detém elevada parcela do mercado: as empresas que cooperam para inovar.

\subsection{Perfil da cooperação para inovar na indústria de transformação}

Empresas que enfrentam dificuldades em reunir competências necessárias para implementar inovações podem unir esforços com outros agentes. A cooperação é fundamental para a inovação, pois amplia o acesso das empresas a uma infinidade de recursos desenvolvidos externamente (Zuniga et al. 2016; Levin et al. 1987). Nesse contexto, fontes internas e externas de insumos para a inovação são vistas como formas complementares, e não substitutas à inovação feita no laboratório próprio de $\mathrm{P} \& \mathrm{D}$ (Cassiman \& Veugelers 2002; Faria, Lima \& Santos 2010).

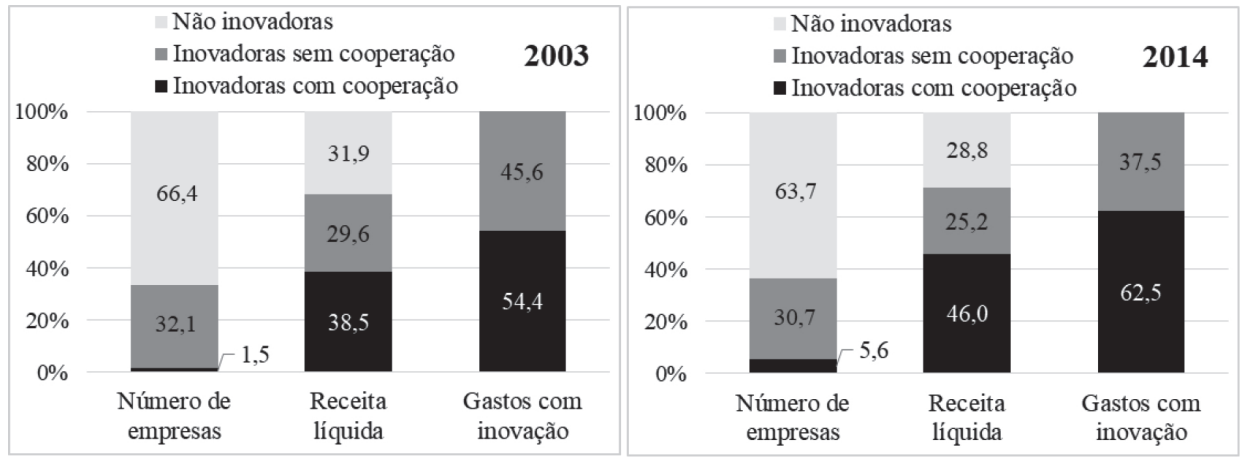

Gráfico 1 - Perfil das empresas da indústria de transformação brasileira, 2003 e 2014 Nota: Não foram consideradas empresas de capital misto. Fonte: Extração especial da Pintec/IBGE. Cálculos e elaboração dos autores.

Do total das empresas da indústria de transformação brasileira, as não inovadoras representaram cerca de dois terços em 2003 e 2014. Um terço restante corresponde às empresas inovadoras, que pode ser dividido entre 
as que cooperaram e as que não cooperaram (Gráfico 1). Embora ainda seja baixo o percentual de empresas que inovam com algum tipo de parceria, a estratégia de cooperar está crescendo entre as empresas manufatureiras. Em 2003, do total de empresas, apenas 1,5\% inovaram e cooperaram, percentual que cresceu para 5,6\% em 2014, o que indica que o número de empresas que cooperou praticamente quadruplicou no período. A participação desse grupo no total da receita líquida e dos gastos inovativos cresceu em torno de $15 \%$, o que indica que, no período, a cooperação se disseminou entre empresas menores.

De fato, as empresas que inovaram com cooperação representam uma ilha de excelência no universo das empresas brasileiras, pois possuem indicadores que se destacam em relação às empresas que inovaram sem realizar algum tipo de parceria, como será visto na sequência. Assim como foi apontado pela literatura (Cohen \& Levinthal 1990; Teece 1998), espera-se que empresas com alto nível de capacitação estejam melhor preparadas para desenvolver projetos com parceiros. Há uma variedade de fatores que levam empresas a estabelecerem arranjos cooperativos para inovar. Em geral, esses fatores relacionam-se com o fato de a empresa não possuir todas as capacidades ou recursos necessários e desejar dividir os riscos associados à inovação (Tether 2002).

No Brasil, a origem do capital controlador tem sido destacada nos estudos de inovação tecnológica devido à elevada presença de filiais de multinacionais estrangeiras no país (Queiroz \& Carvalho 2005; Cassiolato, Matos \& Lastres 2014; Bastos \& Brito 2017; Araújo 2005; Zucoloto \& Cassiolato 2012). Entre 2003 e 2014, nota-se um decréscimo no total de empresas estrangeiras inovadoras de $16 \%$ (Gráfico 2), mesmo num período em que houve um espraiamento da presença de multinacionais aliado a um avanço na internacionalização da atividade tecnológica global.

Quanto às empresas que cooperaram para inovar, praticamente todo o aumento registrado entre 2003 e 2014 deve-se as de controle do capital nacional (Gráfico 2). Apesar da pequena proporção, essas empresas concentraram mais da metade da receita líquida de vendas e dos dispêndios com atividades inovativas (Gráfico 2), tratando-se de um grupo especial a ser estudado. 
Em 2014, as empresas nacionais representaram a maioria das empresas. No entanto, em termos de receita líquida de venda ou gastos com atividades inovativas, empresas de controle estrangeiro que cooperaram para inovar somaram cerca de um quarto do total, e as de controle nacional que cooperaram representaram pouco mais de um terço (Gráfico 2). Além disso, as empresas estrangeiras que cooperaram para inovar tinham maior porte em relação aos demais grupos de empresas (Tabela 2).
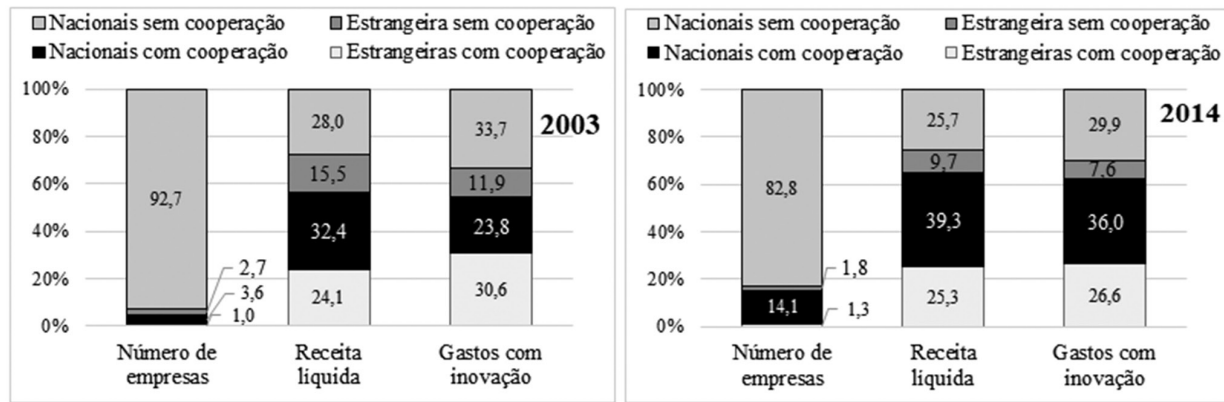

Gráfico 2 - Perfil das empresas inovadoras da indústria de transformação brasileira, por origem do capital e por relação de cooperação para inovar, 2003 e 2014

Nota: Não foram consideradas empresas de capital misto. Fonte: Extração especial da Pintec/IBGE. Cálculos e elaboração dos autores.

Em síntese, os dispêndios com inovação foram feitos, majoritariamente, por empresas que cooperaram para inovar (Gráfico 2). É interessante notar que a estratégia de cooperar para inovar vem sendo crescentemente adotada especialmente por empresas nacionais, visto que além do aumento no número, a parcela delas nos gastos com inovação cresceu 12 pontos percentuais entre 2003 e 2014 (Gráfico 2). Em sentido contrário, no mesmo período, as estrangeiras que cooperaram reduziram sua participação em quatro pontos percentuais.

Os gastos com atividades inovativas sinalizam esforços no sentido de melhorar o acervo tecnológico e promover o desenvolvimento e/ou a implantação de novos produtos ou processos. Além do investimento em P\&D, incluem a aquisição de $\mathrm{P} \& \mathrm{D}$ externa, de conhecimentos externos, de máquinas e equipamentos, treinamento, introdução da inovação no mercado e desenvolvimento do projeto industrial. ${ }^{9} \mathrm{~A}$ intensidade em atividades

9 A aquisição de softwares foi incluída como atividade inovativa em 2014, porém, para manter a base de comparação em relação a 2003, os gastos correspondentes a essa aquisição não foram computados. 
inovativas é dada pela razão dos gastos totais a elas relacionados e a receita líquida de vendas (ver a penúltima coluna da Tabela 2).

A intensidade em $P \& D$ (gastos em $P \& D$ como proporção da receita líquida de vendas) das empresas nacionais que cooperaram praticamente não variou entre 2003 e 2014, mantendo-se próxima de 1,0\% (Tabela 2). Merecem destaque dentro desse grupo as empresas incluídas na categoria de alta tecnologia, que investiram 5,6\% da receita líquida em P\&D em 2014, embora possuam um peso pequeno na estrutura produtiva brasileira.

Entre as empresas nacionais, a diferença em relação às que não cooperaram é significativa, considerando que estas investiram apenas $0,4 \%$ da sua receita líquida em P\&D no mesmo período. Entre as empresas estrangeiras, as que cooperaram tiveram praticamente a mesma intensidade em P\&D que as nacionais que cooperaram (1,1\% em 2014). Além disso, todas as categorias de intensidade tecnológica das empresas estrangeiras que não cooperaram apontaram intensidades em $\mathrm{P} \& \mathrm{D}$ próximas aos grupos das empresas nacionais que também não cooperaram (Tabela 2).

Já a intensidade dos gastos com atividades inovativas mostrou redução em todos os grupos de empresas de 2003 a 2014. Entre as estrangeiras, as que realizaram cooperação mantiveram intensidade superior frente às que não cooperaram, porém, entre as nacionais ocorreu o oposto (Tabela 2). Isso pode indicar que as empresas nacionais que não cooperaram - que estão em maior número e apresentam menor receita líquida - investiram mais em atividades inovativas desenvolvidas por agentes externos e não nos seus próprios laboratórios de $\mathrm{P} \& \mathrm{D}$. Esse tipo de atividade, como aquisição de máquinas e equipamentos direcionados à inovação, apesar de exigir habilidades para realizar a adaptação interna, é considerado de menor esforço em termos de desenvolvimento tecnológico. 
Tabela 2 - Indicadores das empresas inovadoras da indústria de transformação brasileira, 2003 e 2014

\begin{tabular}{|c|c|c|c|c|c|c|c|c|c|}
\hline \multirow[t]{2}{*}{$\begin{array}{l}\text { Grupo de } \\
\text { empresa }\end{array}$} & \multirow[t]{2}{*}{$\begin{array}{l}\text { Intensidade } \\
\text { tecnológica }\end{array}$} & \multicolumn{2}{|c|}{$\begin{array}{c}\text { Receita líquida } \\
\text { (R\$ bilhões de 2016) }\end{array}$} & \multicolumn{2}{|c|}{$\begin{array}{l}\text { P\&D / Receita } \\
\text { líquida (\%) }\end{array}$} & \multicolumn{2}{|c|}{$\begin{array}{l}\text { Atividades inovativas / } \\
\text { Receita líquida (\%) }\end{array}$} & \multicolumn{2}{|c|}{$\begin{array}{l}\text { Receita líquida } \\
\text { média (R\$ milhões } \\
\text { de 2016) }\end{array}$} \\
\hline & & 2003 & 2014 & 2003 & 2014 & 2003 & 2014 & 2003 & 2014 \\
\hline \multirow{5}{*}{$\begin{array}{l}\text { Estrangeiras } \\
\text { com cooperação }\end{array}$} & Baixa & 72,9 & 97,1 & 0,4 & 0,2 & 4,2 & 2,8 & 1.838 & 1.461 \\
\hline & Média-baixa & 50,9 & 89,5 & 0,5 & 0,7 & 3,2 & 2,0 & 1.975 & 1.156 \\
\hline & Média-alta & 234,7 & 297,6 & 1,6 & 1,4 & 4,4 & 3,0 & 2.378 & 1.361 \\
\hline & Alta & 58,5 & 70,8 & 1,2 & 1,3 & 4,8 & 2,8 & 1.629 & 1.256 \\
\hline & Subtotal & 417,1 & 555,0 & 1,2 & 1,1 & 4,3 & 2,8 & 2.085 & 1.325 \\
\hline \multirow{5}{*}{$\begin{array}{c}\text { Estrangeiras } \\
\text { sem cooperação }\end{array}$} & Baixa & 70,9 & 47,6 & 0,1 & 0,3 & 1,6 & 0,9 & 810 & 745 \\
\hline & Média-baixa & 32,8 & 21,2 & 0,4 & 0,6 & 3,5 & 4,6 & 284 & 211 \\
\hline & Média-alta & 134,0 & 113,2 & 0,5 & 0,9 & 2,5 & 2,1 & 459 & 296 \\
\hline & Alta & 30,3 & 31,5 & 0,4 & 1,0 & 4,1 & 1,8 & 564 & 786 \\
\hline & Subtotal & 268,7 & 213,5 & 0,4 & 0,7 & 2,6 & 2,0 & 488 & 364 \\
\hline \multirow{5}{*}{$\begin{array}{l}\text { Nacionais com } \\
\text { cooperação }\end{array}$} & Baixa & 125,0 & 249,1 & 0,2 & 0,5 & 2,0 & 2,5 & 462 & 127 \\
\hline & Média-baixa & 312,2 & 414,5 & 0,6 & 0,8 & 1,5 & 1,8 & 1.511 & 351 \\
\hline & Média-alta & 111,8 & 170,5 & 2,1 & 1,4 & 5,1 & 2,8 & 718 & 147 \\
\hline & Alta & 12,2 & 30,4 & 3,7 & 5,6 & 8,0 & 8,2 & 142 & 77 \\
\hline & Subtotal & 561,3 & 864,5 & 0,9 & 1,0 & 2,5 & 2,4 & 781 & 184 \\
\hline \multirow{5}{*}{$\begin{array}{l}\text { Nacionais sem } \\
\text { cooperação }\end{array}$} & Baixa & 256,9 & 280,6 & 0,2 & 0,2 & 3,8 & 2,6 & 26 & 19 \\
\hline & Média-baixa & 111,6 & 141,0 & 0,3 & 0,4 & 4,0 & 4,0 & 25 & 18 \\
\hline & Média-alta & 94,3 & 125,8 & 0,9 & 0,8 & 4,4 & 2,9 & 26 & 29 \\
\hline & Alta & 23,1 & 17,1 & 1,6 & 1,5 & 5,3 & 4,6 & 28 & 18 \\
\hline & Subtotal & 486,0 & 564,4 & 0,4 & 0,4 & 4,0 & 3,1 & 26 & 21 \\
\hline \multicolumn{2}{|c|}{ Empresas estrangeiras } & 685,8 & 768,5 & 0,9 & 1,0 & 3,6 & 2,6 & 914,2 & 764,0 \\
\hline \multirow{2}{*}{\multicolumn{2}{|c|}{$\begin{array}{l}\text { Empresas nacionais } \\
\text { Ind. de transformação }\end{array}$}} & $1.047,2$ & $1.428,9$ & 0,7 & 0,8 & 3,2 & 2,7 & 54,2 & 44,4 \\
\hline & & $1.733,0$ & $2.197,4$ & 0,7 & 0,9 & 3,3 & 2,6 & 86,4 & 66,2 \\
\hline
\end{tabular}

Nota: Receita Líquida média $=$ razão entre receita líquida e número de empresas. Receita líquida a preços de 2016, calculado pelo deflator do PIB a partir das Contas Nacionais Trimestrais. Fonte: Tabulação especial da Pintec/IBGE. Cálculos e elaboração dos autores.

O porte também pode influenciar a taxa de inovação ao interferir na capacidade da empresa em mobilizar recursos, acessar redes de pesquisa e internalizar novas tecnologias. Segundo estudo de Kannebley Jr., Porto, e Pazello (2004), para as empresas inovadoras brasileiras o tamanho contribui positivamente para a probabilidade de a empresa inovar. Na Tabela 2, nota-se que as empresas nacionais que não cooperaram eram as menores entre os grupos analisados (em termos de receita líquida média). As que cooperaram tinham porte maior, mas, como em 2014 houve aumento expressivo no número de empresas desse grupo sem incremento da receita na mesma dimensão, verifica-se que o porte médio desse grupo caiu em relação a 2003. Empresas estrangeiras que cooperaram destoam na amostra: seu porte médio em 2014 foi sete vezes superior ao das empresas nacionais que cooperaram. 
Os dados das categorias tecnológicas comprovam que setores de maior intensidade tecnológica precisam atualizar-se rapidamente e inovar mais, conforme apontado por Pavitt (1984) e Breschi e Malerba (1997). As categorias de alta e média-alta tecnologia investiram mais em P\&D do que as demais. No Brasil, a receita das empresas inovadoras estrangeiras da indústria de transformação esteve concentrada na categoria de média-alta intensidade tecnológica. Essas empresas possuem cerca de três quintos do market share da receita líquida de vendas total desta categoria tecnológica, assim como na categoria de alta tecnologia (Tabela 2). As empresas de controle estrangeiro de média-alta tecnologia que cooperaram realizaram um esforço tecnológico tão intenso quanto as filiais estadunidenses despenderam fora dos EUA em 2014, embora tenha sido apenas um quarto do que foi gasto dentro dos EUA pela mesma categoria (Tabelas 1 e 2). Isso evidencia o argumento de Zucoloto e Toneto Jr. (2005) de que as empresas de controle estrangeiro despendem esforços menores com suas subsidiárias especialmente nos setores em que a presença delas é majoritária.

Já em relação às empresas nacionais, a receita se concentrou em baixa e média-baixa tecnologia, de acordo com o padrão de especialização da manufatura nacional que concentra cerca de dois terços da produção nessas categorias tecnológicas (Morceiro 2018). Por sua vez, as empresas nacionais de média-baixa tecnologia que cooperaram investiram em $\mathrm{P} \& \mathrm{D}$ um percentual maior do que as multinacionais estadunidenses investiram no seu país e fora dele (Tabelas 1 e 2). Vale mencionar que a maior proximidade dos esforços inovativos brasileiros do padrão internacional em setores de menor intensidade tecnológica é um elemento importante da dinâmica inovativa no Brasil já apontado pela literatura (Furtado \& Carvalho 2005; Zucoloto \& Toneto Jr. 2005).

Em geral, os setores de baixa tecnologia são assim classificados pelo menor percentual de investimentos em $\mathrm{P} \& \mathrm{D}$ em relação à receita, mas conforme descrito por Furtado e Carvalho (2005), a alocação dos setores por intensidade tecnológica pode variar para o caso brasileiro. É verdade que nesse grupo a intensidade de gastos em outras atividades inovativas é maior do que a intensidade em $\mathrm{P} \& \mathrm{D}$, no entanto, o mesmo é válido para a maioria das outras categorias. Pavitt (1984) descreve esses setores como dominados por fornecedores, uma vez que dependem de tecnologias e inovações feitas em outros setores. Nesta categoria, as empresas nacionais que cooperaram alocaram em atividades inovativas em 2014 cinco vezes o montante gasto com $\mathrm{P} \& \mathrm{D}$, enquanto dentre as nacionais que não cooperaram o volume foi 13 vezes superior. As empresas estrangeiras que cooperaram foram as que 
mais despenderam recursos em atividades inovativas proporcionalmente à sua receita líquida de vendas: elas aplicaram 14 vezes o montante destinado à $\mathrm{P} \& \mathrm{D}$, enquanto as estrangeiras que não cooperaram investiram o triplo nessas atividades. Isso ocorre porque, embora as empresas de baixa tecnologia sejam assim classificadas em razão do menor investimento em $\mathrm{P} \& \mathrm{D}$, elas executam outros tipos de atividades inovativas, principalmente a aquisição de máquinas e equipamentos (conforme será mostrado adiante). A categoria de baixa tecnologia demanda componentes tecnológicos, máquinas e equipamentos das categorias de média-alta e alta tecnologia, que são indiretamente responsáveis pelo desenvolvimento tecnológico dos seus clientes. Assim, P\&D não é um fator delimitador da atividade inovativa das empresas de menor intensidade tecnológica, pois essas categorias absorvem inovações incorporadas nos produtos tecnológicos que elas compram.

\subsection{Parceiros das empresas na cooperação para inovar}

$\mathrm{Na}$ Pintec as empresas indicam quais parcerias realizaram para inovar e qual sua importância (alta, média, baixa ou irrelevante). Para captar as parcerias de maior impacto, foram consideradas apenas as de alta importância. O eixo vertical do Gráfico 3 indica a proporção de empresas em cada categoria tecnológica que se relacionou com o tipo de parceiro citado, sendo que uma mesma empresa pode fazer parcerias com mais de um ator do sistema.

Entre as empresas nacionais a cooperação foi realizada preponderantemente com dois parceiros: clientes e fornecedores, que estão em contato frequente para estabelecer parcerias estratégicas, acompanhar o processo produtivo e verificar possíveis adaptações sobre propriedades e requisitos técnicos do produto adquirido (Cohen \& Levintal 1990). Como a funcionalidade do produto depende dos seus componentes, peças e subsistemas interligados, desse trabalho conjunto surgem soluções de problemas e/ou demandas que modificam os insumos e conferem novas características ao bem final. A relação entre usuários e produtores de bens de capital também é crucial em alguns processos inovativos que precisam desenvolver ou adaptar máquinas e equipamentos para a produção de um produto novo (Lundvall 1992). Neste ponto, os feedbacks apontados por Bell (1984) e Kline e Rosenberg (1986) entre uma área da empresa e clientes ou fornecedores são os principais insumos da parceria. Por exemplo, no setor de 
produtos plásticos é comum que empresas contatem seus fornecedores de resinas petroquímicas para discutirem projetos de adaptação no insumo a fim de alterar o produto final. As demandas incluem a necessidade de produzir peças mais rígidas e resistentes a choques ou nova formulação que permita moldar o produto a temperaturas mais elevadas sem perder as características.

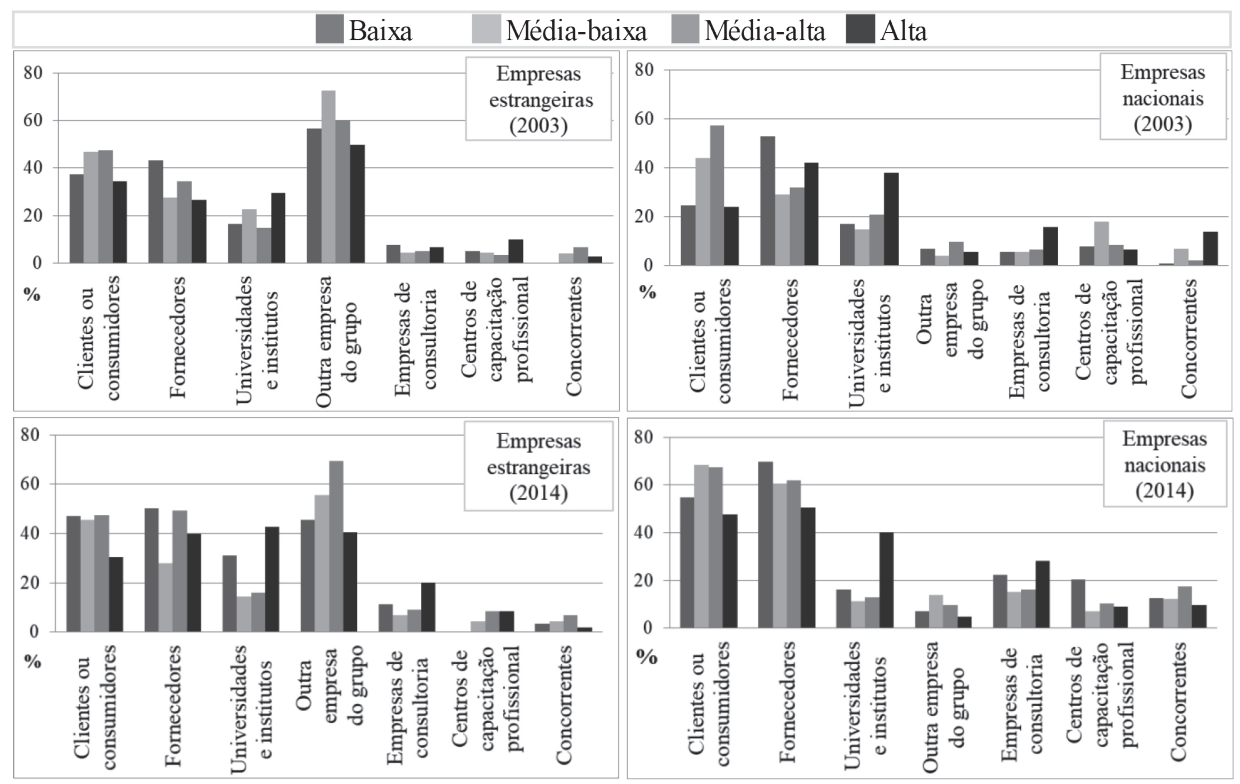

Gráfico 3 - Parceiros utilizados na cooperação para inovar por grupos de empresas, 2003 e 2014 (\%)

Nota: uma empresa pode cooperar com mais de uma opção e por isso a soma das parcerias supera $100 \%$ em cada grupo de empresa. Fonte: Tabulação especial da Pintec/IBGE. Elaboração dos autores.

Segundo Erber (2010), as empresas brasileiras que inovaram mais em produtos estabeleceram mais parcerias com clientes e consumidores, enquanto as empresas que focaram as inovações em processos utilizaram os fornecedores mais assiduamente. As empresas cooperam com seus consumidores ao divulgar ou oferecer produtos em fase de teste ou pré-lançamento, buscando aumentar as chances de os clientes aprovarem a inovação. Consequentemente, conhecem as preferências dos seus consumidores, aumentam a confiança dos usuários em seus produtos e reduzem os riscos associados ao lançamento da inovação no mercado (Tether 2002; Kline \& 
Rosenberg 1986). Por sua vez, a cooperação com fornecedores compartilha muitas das razões da relação com consumidores. Mas no caso dos fornecedores, envolve também decisões estratégicas para obter maior eficiência na produção e focalização em competências centrais (Tether 2002; Faria, Lima \& Santos 2010).

A interação com universidades e institutos de pesquisas não foi fortemente utilizada por empresas nacionais quando comparada com os demais parceiros, exceto no caso de alta tecnologia (Gráfico 3). No entanto, quando comparada ao contexto internacional, essa proporção em geral não é baixa. Pinho (2011) identificou que a média de empresas que consideram a parceria com universidades relevante é maior no Brasil do que nos países da União Europeia. A capacidade de absorção das empresas é determinante para estabelecer a cooperação, dado que envolve apropriação de conhecimentos externos (Cassiman \& Veugelers 2002), por isso, nem todas as empresas estão aptas a estabelecer parcerias de maior complexidade.

A interação com a universidade ocorre quando são requeridos conhecimentos específicos para solucionar problemas que demandam pesquisa técnica (Kline \& Rosenberg 1986). No entanto, no Brasil, as universidades e institutos de pesquisa, assim como outras estruturas científicas, foram instaladas tardiamente em comparação aos países desenvolvidos (Suzigan et al. 2009). A principal universidade do país, a Universidade de São Paulo (USP), tem menos de 100 anos de existência, enquanto várias universidades europeias atuam há mais de quatro séculos. Há diversas formas de a universidade auxiliar no desenvolvimento tecnológico das empresas, por exemplo, por meio de novos instrumentos, técnicas e avanço no conhecimento científico (Fernandes et al. 2010), desenvolvimento de pesquisas que não realiza internamente, utilização de recursos disponíveis na universidade ou instituto, realização de pesquisa conjunta ou encomendada, contratação de pessoal e troca informal de informações (Pinho 2011).

Para as empresas estrangeiras, as parcerias feitas com fornecedores e clientes estão entre as mais relevantes, principalmente para a categoria de média-alta tecnologia. Porém, a principal forma de cooperação ocorre com outra empresa do grupo, com maior valor para categorias de média-alta e média-baixa tecnologia. Ademais, Tessarin (2018) revelou que a outra empresa do grupo está predominantemente localizada no exterior. Conforme Zucoloto e Cassiolato (2012), as filiais de multinacionais operam no Brasil com foco na adaptação de produtos e processos ao mercado local, assim, a 
cooperação com a matriz torna-se de extrema relevância. Caso a cooperação tenha como objetivo adaptar o projeto feito por outra firma do grupo, o potencial de transbordamento tecnológico local é limitado. Nesse caso, a inovação ocorre para tropicalizar a tecnologia, ou seja, reproduzir o projeto desenvolvido no exterior e adequá-lo ao contexto do país hospedeiro ${ }^{10}$ (Consoni 2004). Apesar do esforço tecnológico de adaptação envolvido, a essência da tecnologia foi desenvolvida no exterior. Esse tipo de cooperação com outra empresa do grupo é pouco visto entre as empresas nacionais de qualquer categoria tecnológica no período. Tal fato pode indicar a pequena quantidade de grandes grupos empresariais de capital nacional, de acordo com Kannebley Jr., Porto, e Pazello (2004). Esses autores identificaram que, no Brasil, as empresas inovadoras são majoritariamente independentes, ou seja, não fazem parte de um grupo empresarial.

Outras instituições, como empresas de consultoria, centros de capacitação profissional e concorrentes, são menos utilizadas pelas empresas, sejam elas nacionais ou estrangeiras. No caso dos concorrentes, por um lado, pode ser uma opção das empresas não compartilhar informações com seus competidores diretos, mas, por outro, mostra que é muito rara uma estratégia de compartilhamento de custos e riscos associados ao desenvolvimento de um projeto estagnado que seria de interesse para ambos (Kannebley Jr., Porto, \& Pazello 2004). Concorrentes poderiam cooperar quando enfrentam problemas similares, especialmente de cunho técnico ou regulatório. Também há evidências de novas empresas concorrentes entre si que decidem colaborar para fazer frente a um terceiro concorrente maior e estabelecido há mais tempo no mercado (Tether 2002). Quanto aos centros de capacitação profissional, são empresas de capital nacional e de menor porte (menos de 500 empregados) que utilizam mais esse tipo de cooperação (Bastos \& Britto 2017).

${ }^{10}$ Alguns exemplos conhecidos são: a adaptação da resistência de pneus automotivos para que sejam eficientes e suportem a elevada temperatura do asfalto no Brasil; a adaptação de produtos elétricos para a voltagem das residências brasileiras, que ainda pode diferir entre as regiões do país; a adaptação de produtos de higiene pessoal às características da população, principalmente em produtos para a pele e proteção solar. 
Outra hipótese, não investigada neste artigo, é a de que a cooperação para inovar se manifeste principalmente nos aprendizados do tipo learning-by- doing (Arrow 1962). Essa interação tende a ser mais corriqueira porque faz parte da rotina operacional das empresas e se aproveita de feedbacks existentes na cadeia de produção, os quais fornecem ideias e insumos para melhoramentos e adaptações que resultam em inovações no produto final (Bell 1984; Kline \& Rosenberg 1986).

\subsection{Fontes das informações que dão origem à inovação}

As empresas podem consultar diversas fontes de informação para obter inspiração e orientação nos projetos de inovação (IBGE 2004). A Pintec agrega uma lista com 14 fontes de informação geralmente consultadas por empresas no decorrer do processo inovativo (apresentadas no Gráfico 4). Elas representam a capacidade das empresas de obter informação e auxiliam na compreensão sobre como surgem as inovações. Além disso, elucidam o alcance das redes organizacionais (Britto \& Powell 1990) e o poder de conexão com outros elos.

As informações obtidas a partir de fontes externas para inovar, como fornecedores e clientes (pontos 4 e 5 do Gráfico 4, respectivamente), e outras áreas da empresa (ponto 2 do Gráfico 4) foram consideradas como mais relevantes pelas empresas inovadoras em geral. Lundvall (1992) indicou que clientes e fornecedores são os tipos de parceiros mais usual para estimular o aprendizado pela prática. Para as empresas nacionais, informações oriundas de concorrentes (pontos 6) e redes de informação (ponto 14, por exemplo, internet) também são muito relevantes, com exceção da categoria de alta tecnologia no primeiro caso. As redes são geralmente de fácil acesso e não possuem elevado custo de entrada. Além disso, a maior parte das inovações no Brasil é inédita para a empresa e não para o mercado, o que pode explicar a presença dos concorrentes como fonte de informação. As fontes de informação anteriormente mencionadas exigem menor esforço tecnológico - comparativamente ao departamento de P\&D e interações com universidades e institutos de pesquisa. Elas estão relacionadas com a forma com que a inovação é realizada, maciçamente via aprimoramentos para a empresa ao invés de inovações de dimensão nacional. 

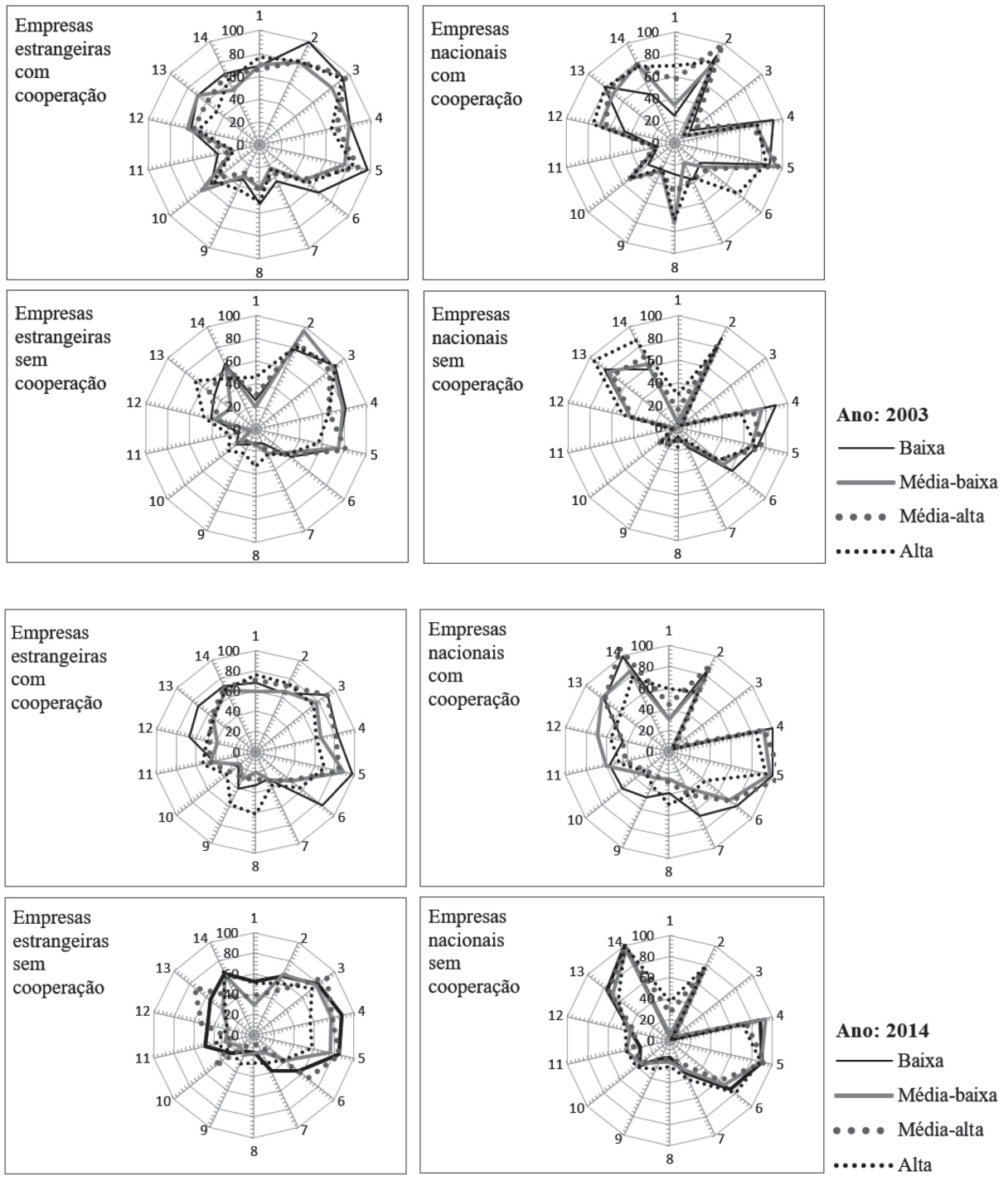

1- Departamento de P\&D 6 - Concorrentes

2 - Outras áreas da empresa 7 - Empresas de consultoria

3 - Outra empresa do grupo 8 - Universidades e institutos de pesquisa

4 - Fornecedores 9 - Centros de capacitação profissional

11 - Licenças e patentes

12 - Conferências e publicações

13 - Feiras e exposições

5 - Clientes ou consumidores 10 - Instituições de testes e certificações

14 - Redes de informação

Gráfico 4 - Fontes de informação utilizadas para inovar pela manufatura brasileira, em $\%$ do total dos grupos de empresas, 2003 e 2014

Nota: os eixos representam o percentual de empresas em cada categoria de intensidade tecnológica que avaliou a fonte com alto grau de importância.

Fonte: Extração especial da Pintec/IBGE. Cálculos e elaboração dos autores. 
Além de clientes e fornecedores, a importância atribuída em geral pelas empresas estrangeiras às informações originárias de outras empresas de seu grupo foi grande em 2003 e 2014 (Gráfico 4), enquanto outra área da empresa (ponto 2 do Gráfico 4) perdeu espaço em 2014. Conforme apontado anteriormente, as parcerias utilizadas pelas empresas estrangeiras que cooperaram também foram baseadas em outras empresas de seu grupo. Isso reforça a suspeita de alguns autores como Araújo (2005) e Zucoloto e Cassiolato (2012) de que os esforços inovativos empreendidos pelas empresas multinacionais são mais voltados para adaptação de produtos e processos do que necessariamente à criação de novas soluções. No caso das empresas nacionais, informações oriundas de outra empresa do grupo são praticamente inexistentes. Do ponto de vista do país, se, por um lado, essas empresas trazem ao Brasil atualização tecnológica, por outro lado, não estabelecem conexão com organizações locais para internalizar tais conhecimentos (Consoni 2004; Cassiolato, Matos \& Lastres 2014).

As universidades e centros de capacitação profissional foram moderadamente consultados pelas empresas estrangeiras que cooperaram da categoria de alta tecnologia. Dado que essas fontes de informação dependem de uma base de conhecimento previamente estabelecida, elas sugerem atividades mais prolongadas de cooperação (Cassiman \& Vegelers 2002). Empresas nacionais e estrangeiras que cooperaram se mostraram mais adaptadas para realizar essas parcerias porque foram as que mais fizeram P\&D.

\subsection{Síntese dos esforços inovativos}

A Tabela 3 resume as informações a respeito do esforço inovativo realizado pelas empresas no Brasil em 2014. As empresas inovadoras da indústria de transformação investiram $2,6 \%$ da sua receita líquida em atividades inovativas em 2014 (Tabela 3). Comparativamente, esse percentual equivale ao destinado apenas à $\mathrm{P} \& \mathrm{D}$ pelos países da OCDE. Dentre as atividades inovativas, a aquisição de máquinas e equipamentos para implementar produtos ou processos novos ou tecnologicamente aperfeiçoados foi a principal atividade inovativa, realizada com $42 \%$ dos gastos totais e, na sequência, P\&D interna com 33\%. Pode-se conhecer o tipo de atividade inovativa realizada com maior frequência por cada categoria tecnológica no trabalho de Tessarin (2018). 
Atividades internas de $P \& D$, aquisição de $P \& D$ externa e aquisição de outros conhecimentos são particularmente importantes para gerar inovações (Cassiman \& Veugelers 2002). No caso da aquisição de máquinas e equipamentos, requer-se no mínimo assimilação tecnológica e treinamento para colocar a máquina em uso, o que promove um aprendizado passivo (Lundvall 1992). A complexidade envolvida no processo inovativo certamente é menor, mas podemos dividi-la em dois tipos: um passivo, que permite à empresa ampliar sua produtividade via instalação de máquinas e equipamentos modernos com poucas modificações no layout produtivo e/ou nas áreas de estocagem e comercialização; e outro ativo, que exige absorção significativa de novos conhecimentos e modificações de maior monta no funcionamento regular da empresa. Contudo, a predominância da inovação pela aquisição de máquinas e equipamentos é uma característica de empresas dominadas pelos fornecedores, que dependem do progresso tecnológico embutido nos bens de capital desenvolvidos por empresas especializadas (Pavitt 1984).

As empresas nacionais sem cooperação para inovar buscaram, em geral, melhorar a qualidade dos produtos ao se basear em redes de informação e inovações de processo, essencialmente via aquisição de máquinas e equipamentos, destinando pequeno percentual da receita para P\&D. Vale destacar que essas empresas são as de menor porte (em termos de receita média) em comparação com as demais analisadas. As empresas estrangeiras que não cooperaram para inovar distinguem seu perfil entre os grupos de menor e maior intensidade tecnológica. Na média, as categorias de baixa e média-baixa tecnologia apresentaram perfil comparável com empresas nacionais sem cooperação. Por sua vez, as categorias de média-alta e alta tecnologia realizam mais P\&D interna e basearam-se em informações originadas em outras empresas do grupo. 


\begin{tabular}{|c|c|c|c|c|c|c|c|c|c|c|}
\hline 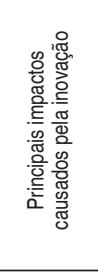 & 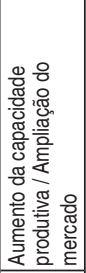 & 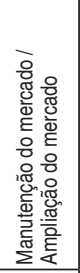 & 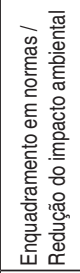 & 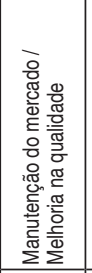 & 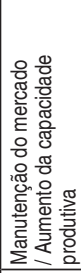 & 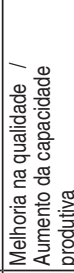 & 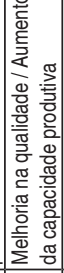 & 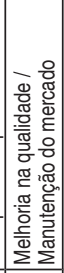 & 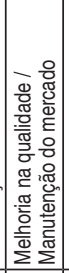 & 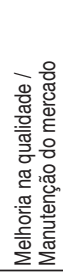 \\
\hline 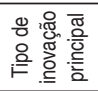 & 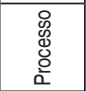 & 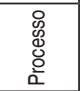 & 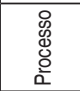 & 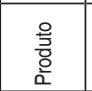 & 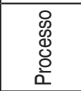 & $\begin{array}{l} \\
\\
o \\
o \\
o \\
\stackrel{\circ}{2}\end{array}$ & 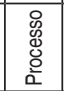 & 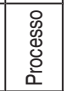 & 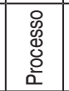 & $\begin{array}{l} \\
\stackrel{0}{0} \\
\stackrel{0}{0} \\
\stackrel{0}{2}\end{array}$ \\
\hline 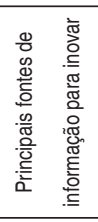 & 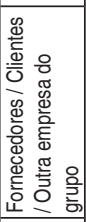 & 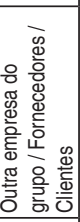 & 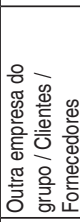 & 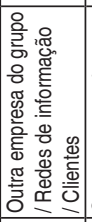 & 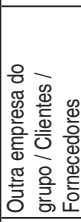 & 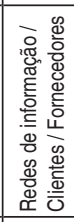 & 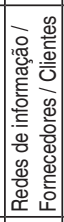 & 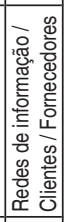 & 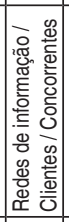 & 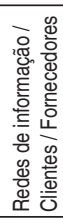 \\
\hline 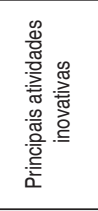 & 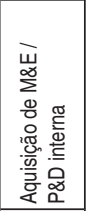 & 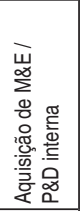 & 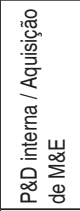 & 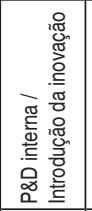 & 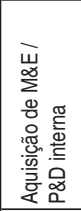 & 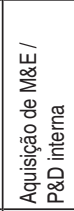 & 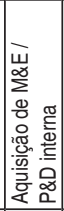 & 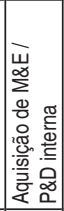 & 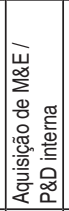 & 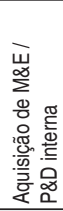 \\
\hline 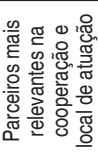 & & & & & & . & . & & & \\
\hline 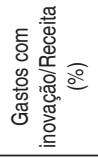 & O্ণ & 志 & 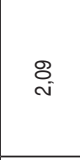 & 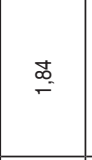 & $\stackrel{\sim}{\sim}$ & 虽 & $\underset{+}{+}$ & $\underset{\sim}{\stackrel{\sim}{~}}$ & 㔔 & $\hat{e}_{\vec{j}}$ \\
\hline 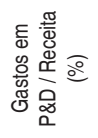 & \begin{tabular}{l}
$\stackrel{̊}{0}$ \\
\hdashline
\end{tabular} & ฮั & $\begin{array}{l}\hat{\infty} \\
0 \\
0\end{array}$ & क् & $\underset{0}{\mathbb{N}}$ & ָู & Fo & $\begin{array}{l}\mathscr{\infty} \\
\infty \\
0\end{array}$ & 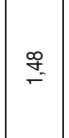 & 某 \\
\hline 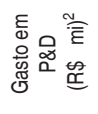 & $\overline{\tilde{N}}$ & 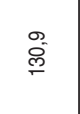 & $\begin{array}{l}\mathscr{\infty} \\
\infty\end{array}$ & 穴 & 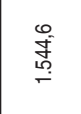 & స్లై & é & 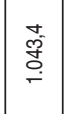 & 总 & స̃ \\
\hline 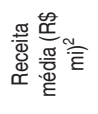 & 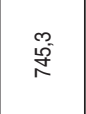 & $\stackrel{-}{i}$ & 㐫 & 芯 & $\hat{\text { ह్ల }}$ & $\stackrel{\leftrightarrow}{\circ}$ & 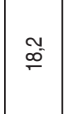 & $\stackrel{\widehat{o}}{\stackrel{\sim}{N}}$ & $\stackrel{\infty}{\infty}$ & 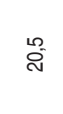 \\
\hline 要 & $\stackrel{\sim}{\sim}$ & $\stackrel{8}{8}$ & $\frac{6}{5}$ & $\stackrel{g}{-}$ & No & 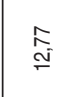 & צ̃ & $\underset{\text { in }}{\mathbb{N}}$ & $\begin{array}{l}\infty \\
\stackrel{\infty}{0} \\
0\end{array}$ & $\begin{array}{l}\infty \\
\stackrel{\infty}{\infty} \\
\stackrel{2}{n}\end{array}$ \\
\hline 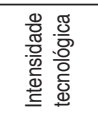 & 哸 & 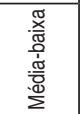 & 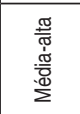 & $\frac{\frac{\pi}{6}}{\frac{3}{\alpha}}$ & 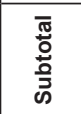 & 戙 & 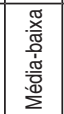 & 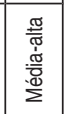 & $\frac{\pi}{\frac{\pi}{\alpha}}$ & 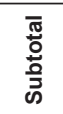 \\
\hline 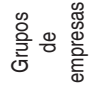 & \multicolumn{5}{|c|}{ 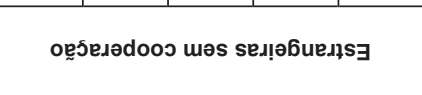 } & \multicolumn{5}{|c|}{ oeşexədooo məs s!̣euo!̣en } \\
\hline
\end{tabular}




\begin{tabular}{|c|c|c|c|c|c|c|c|c|c|c|c|c|c|c|}
\hline 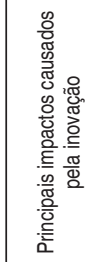 & 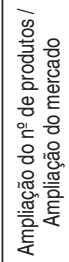 & 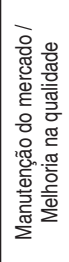 & 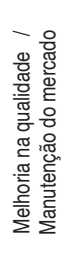 & 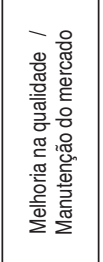 & 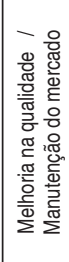 & 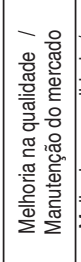 & 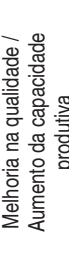 & 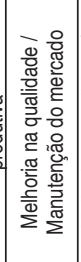 & 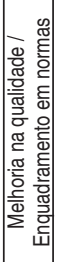 & 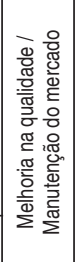 & 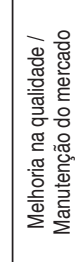 & 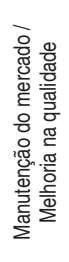 & 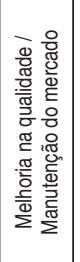 & 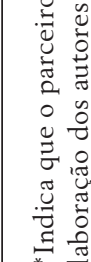 \\
\hline 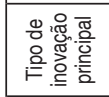 & 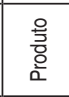 & 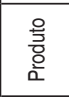 & 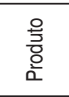 & 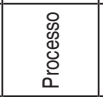 & $\begin{array}{l}\text { 음 } \\
\text { 홈 } \\
\end{array}$ & $\begin{array}{l}\circ \\
.0 \\
\& \\
\frac{0}{2} \\
\end{array}$ & $\begin{array}{l}0 \\
\stackrel{0}{0} \\
\stackrel{0}{0} \\
\end{array}$ & 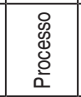 & 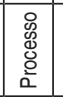 & 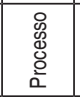 & 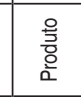 & 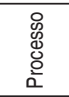 & 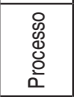 & \\
\hline 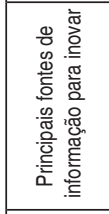 & 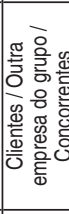 & 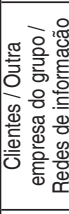 & 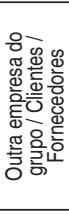 & 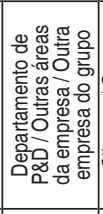 & 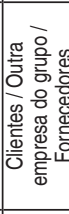 & 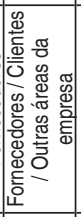 & 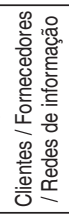 & 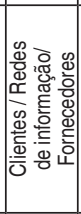 & 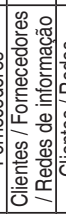 & 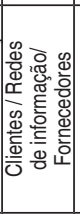 & 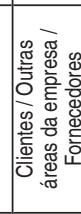 & 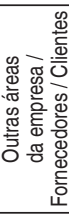 & 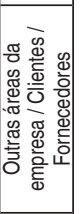 & 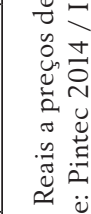 \\
\hline 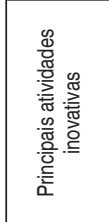 & 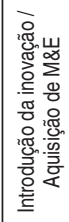 & 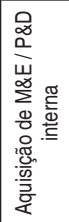 & 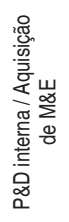 & 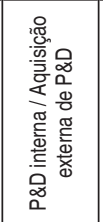 & 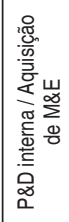 & 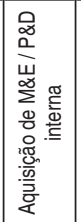 & 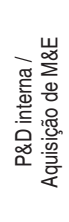 & 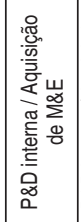 & 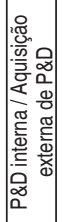 & 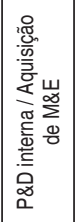 & 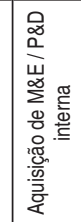 & 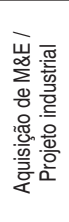 & 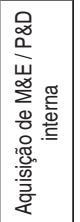 & 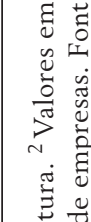 \\
\hline 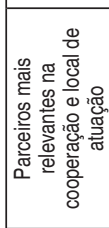 & 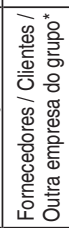 & 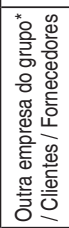 & 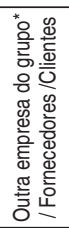 & 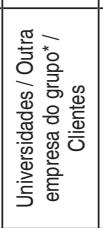 & 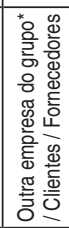 & 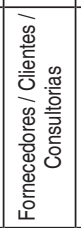 & 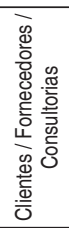 & 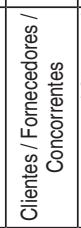 & 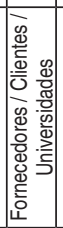 & 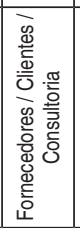 & 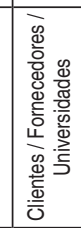 & & 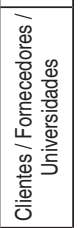 & 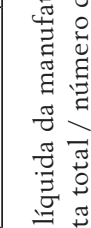 \\
\hline 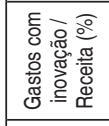 & 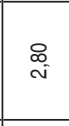 & $\stackrel{\leftrightarrow}{\stackrel{\leftrightarrow}{\sigma}}$ & $\underset{\sim}{\stackrel{8}{\sim}}$ & $\underset{\sim}{\stackrel{D}{\sim}}$ & $\underset{\sim}{N}$ & 守 & $\stackrel{I}{=}$ & $\underset{\substack{d \\
\text { d }}}{ }$ & $\stackrel{\infty}{\infty}$ & $\underset{\sim}{\sigma}$ & $\stackrel{5}{i n}$ & $\stackrel{\infty}{\sim}$ & în & $\bar{U}$ \\
\hline 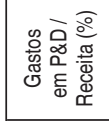 & $\stackrel{\text { No }}{0}$ & \& & $\underset{\mathcal{F}}{\sim}$ & 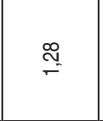 & $\stackrel{\infty}{:}$ & $\begin{array}{l}0 \\
0 \\
0\end{array}$ & $\begin{array}{l}\stackrel{2}{\infty} \\
0\end{array}$ & $\stackrel{0}{q}$ & 趈 & $\stackrel{5}{=}$ & $\stackrel{t}{\stackrel{\Delta}{r}}$ & ָั & \begin{tabular}{l}
$\cong$ \\
\hdashline \\
0
\end{tabular} & 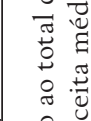 \\
\hline 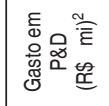 & 吕 & $\frac{\overline{0}}{0}$ & 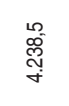 & $\begin{array}{l}\infty \\
\text { o }^{\infty} \\
\sigma^{\infty}\end{array}$ & 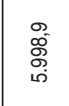 & 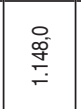 & 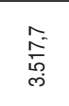 & & 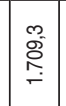 & $\begin{array}{l}\text { o } \\
h \\
\infty \\
\infty\end{array}$ & 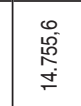 & 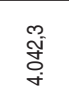 & $\begin{array}{l}\stackrel{9}{0} \\
\stackrel{2}{\alpha} \\
\infty \\
\infty\end{array}$ & $\pi$ \\
\hline 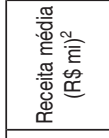 & 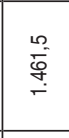 & 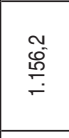 & $\begin{array}{l}\stackrel{0}{\overline{0}} \\
\stackrel{0}{\circ}\end{array}$ & 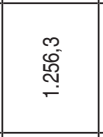 & 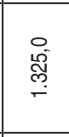 & 몽 & $\stackrel{n}{i}$ & $\begin{array}{l}0 \\
\stackrel{o}{o g} \\
\dot{q}\end{array}$ & $\stackrel{\infty}{0}_{0}^{\infty}$ & $\begin{array}{l}\text { N } \\
\underset{\Phi}{\Phi}\end{array}$ & $\hat{\hat{N}}$ & $\hat{N}$ & $\stackrel{\pi}{8}$ & $\vec{\sigma}$ \\
\hline 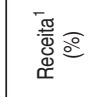 & $\underset{z}{Z}$ & o & 芯 & $\underset{\sim}{\widetilde{\infty}}$ & $\begin{array}{l}\stackrel{0}{1} \\
\stackrel{\sim}{N}\end{array}$ & 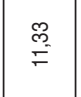 & $\begin{array}{l}\infty \\
\infty \\
\stackrel{\infty}{\circ}\end{array}$ & $\stackrel{2}{\curvearrowright}$ & $\stackrel{\infty}{\stackrel{m}{\sim}}$ & 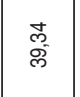 & \begin{tabular}{l}
8 \\
\multirow{0}{0}{}
\end{tabular} & $\begin{array}{l}\text { g } \\
\text { s. }\end{array}$ & $\begin{array}{l}8 \\
0 \\
0\end{array}$ & \\
\hline 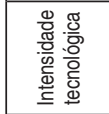 & 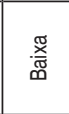 & 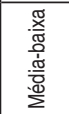 & 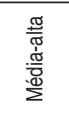 & $\frac{⿱ \pi}{4}$ & 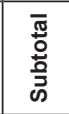 & 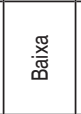 & 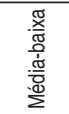 & 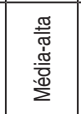 & $\frac{\pi}{4}$ & 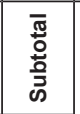 & \multirow{2}{*}{ 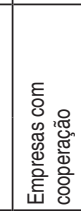 } & \multirow{2}{*}{ 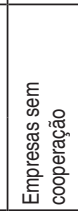 } & \multirow{2}{*}{ 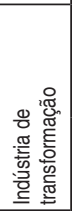 } & \\
\hline 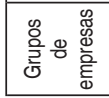 & \multicolumn{5}{|c|}{ 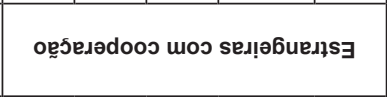 } & oes & גəäc & wos & s!̣euo & Nיאן & & & & 2 \\
\hline
\end{tabular}


Já as empresas que cooperaram para inovar desenvolveram estratégias de inovação mais ativas e empreenderam esforços maiores para inovar. O percentual gasto tanto em P\&D como em atividades inovativas foi similar entre as empresas nacionais e estrangeiras (Tabela 3). No entanto, os esforços das empresas estrangeiras diferem de acordo com a intensidade tecnológica. Dentre as categorias de baixa e média-baixa tecnologia as atividades inovativas basearam-se em informações de clientes e envolveram gastos com a introdução da inovação no mercado e aquisição de máquinas para resultarem em inovações de produto. Entre as categorias de alta e média-alta tecnologia a P\&D foi a principal atividade inovativa, a cooperação foi feita essencialmente com universidades e outra empresa do grupo localizada no exterior, e as informações para inovar vieram de outra empresa do grupo ou departamento de P\&D próprio.

Dentre as empresas nacionais que cooperaram destacam-se os elevados gastos com P\&D, especialmente do grupo de alta tecnologia (Tabela 3) no qual a intensidade em $P \& D$ foi 3,4 vezes superior à realizada por empresas estrangeiras que cooperaram do mesmo grupo. É interessante notar que tanto o parceiro da cooperação como as fontes de informação para inovar são clientes e fornecedores.

\section{Conclusão}

Verificou-se nesta pesquisa que a cooperação para inovar é um fator de diferenciação no esforço inovativo das empresas segundo categorias de intensidade tecnológica e origem do capital controlador. Para tanto, explorou-se uma tabulação especial inédita da Pintec/IBGE dos períodos de 2001-2003 e 2012-2014 para a indústria de transformação. Além da cooperação com universidades e institutos de pesquisa enfatizadas na literatura, foram incluídas na análise a cooperação com outros agentes para verificar se eles são realmente relevantes para o esforço inovativo no Brasil. Neste contexto, foi possível contribuir com a literatura ao identificar algumas diferenças no impacto da cooperação, envolvendo distinções em termos de categorias de intensidade tecnológica e origem do capital.

O artigo contribui com a literatura ao considerar outros parceiros na cooperação para inovar, pois identificou que as relações de cooperação para todas as categorias tecnológicas envolveram principalmente parceiros com 
quem a empresa mantém relação produtiva direta (clientes e fornecedores). A cooperação com universidades e institutos de pesquisa, frequentemente enfatizada pela literatura, ocorreu moderadamente apenas com empresas nacionais de alta tecnologia. Por sua vez, a cooperação com outra empresa do grupo é intensa entre empresas de capital estrangeiro, porém pouco frequente entre as de capital nacional.

Os resultados mostraram que não há uma diferença significativa nos esforços inovativos das empresas considerando a origem do capital, independentemente da categoria de intensidade tecnológica. No entanto, a diferença é substantiva entre as empresas que cooperaram para inovar frente às que não cooperaram.

As empresas que inovaram sem relação de cooperação (cinco sextos das inovadoras), sejam de controle do capital nacional ou estrangeiro, basearam suas atividades inovativas em agentes externos. As inovações foram introduzidas a partir de informações obtidas com fornecedores, clientes e redes de informação e os dispêndios inovativos concentraram-se na aquisição de máquinas e equipamentos. Essas empresas seguiram uma trajetória de inovação menos arriscada, baseada na manutenção do market share; assim, seu esforço inovativo e desempenho inovador foram limitados comparativamente às empresas que inovaram com cooperação.

O subconjunto de empresas que cooperaram para inovar reuniu quase dois terços da receita líquida de vendas e dos dispêndios com atividades inovativas das empresas inovadoras, embora em número representassem apenas um sexto delas. Por isso, considera-se que as empresas que inovaram com cooperação representam uma ilha de excelência no universo das empresas inovadoras brasileiras. Em geral, as empresas que cooperaram para inovar mostraram-se mais aptas a desenvolver atividades inovativas de longo prazo (como a P\&D interna) e habilidades para internalizar conhecimentos e tecnologias externas, assim como desenvolvê-las em conjunto. As empresas de controle nacional empreenderam um esforço inovativo similar ao das empresas estrangeiras, embora não tivessem a opção de contatar outras empresas do grupo para obter informações para inovar, como fazem as estrangeiras instaladas no Brasil. Como resultado da inovação, além de manter a parcela de mercado, as inovações produziram melhorias nos produtos.

Quanto às empresas estrangeiras que cooperaram, é válido destacar que sua estratégia inovativa é fortemente baseada em outras empresas do seu grupo localizadas no exterior - tanto como fonte de informação consul- 
tada quanto dos parceiros utilizados na cooperação. Uma das hipóteses consideradas é a de que a atividade inovativa realizada por elas é do tipo adaptativa e têm como objetivo a manutenção do mercado. É provável que a estratégia dessas empresas envolva o alinhamento de descobertas feitas no exterior às características da demanda local - em vista do atrativo tamanho do mercado doméstico brasileiro - sem que para isso seja necessário um significativo esforço inovativo. Esse perfil adaptativo (tropicalização) é mencionado setorialmente pela literatura e este estudo forneceu mais indícios de que ele é generalizado no Brasil.

\section{Referências}

Abramovsky, Laura, Elisabeth Kremp, Alberto López, Tobias Schmidt, and Helen Simpson. 2009. "Understanding Co-Operative Innovative Activity: Evidence from Four European Countries.” Economics of Innovation and New Technology 18, no. 3 (April): 243-65. https://doi.org/10.1080/10438590801940934.

Albuquerque, Eduardo Da Motta E, Leandro Silva, and Luciano Póvoa. 2005. "Diferenciação Intersetorial Na Interação Entre Empresas e Universidades No Brasil.” São Paulo Em Perspectiva 19, no. 1: 95-104. https://doi. org/10.1590/S0102-88392005000100008.

Araújo, Rogério Dias de. 2005. “Esforços Tecnológicos Das Firmas Transnacionais e Domésticas.” In: Inovações, Padrões Tecnológicos e Desempenho Das Firmas Indústriais Brasileiras, edited by Alberto De Negri and Mario Sergio Salerno, 119-70. Brasilia: IPEA.

Arrow, Kenneth J. 1962. "The Economic Implications of Learning by Doing." The Quarterly Journal of Economics 29, no. 3: 155-73.

Bastos, Carlos Pinkusfeld, and Jorge Britto. 2017. "Inovação e Geração de Conhecimento Científico e Tecnológico No Brasil: Uma Análise Dos Dados de Cooperação Da Pintec Segundo Porte e Origem de Capital.” Revista Brasileira de Inovação 16, no. 1: 35-62.

Bell, Martin. 1984. “'Learning' and the Accumulation of Industrial Technological Capacity in Developing Countries." In Technological Capability in the Third World, edited by M Fransman and K King, 187-209. London: Palgrave Macmillan. https://doi.org/10.1007/978-1-349-17487-4_10.

Breschi, Stefano, and Franco Malerba. 1997. "Sectoral Innovation Systems: Technological Regimes, Schumpeterian Dynamics, and Spatial Boundaries." In Systems of Innovation: Technologies, Institutions and Organizations, edited by C Edquist, 130-56. London: Pinter A Cassell.

Britto, Jorge. 2002. “Cooperação Interindustrial e Redes de Empresas.” In Economia Industrial: Fundamentos Teóricos e Práticos No Brasil, edited by D. Kupfer and L. Hasenclever, 211-30. Rio de Janeiro: Campus. https:// doi.org/10.1016/B978-85-352-6368-8.00016-5.

Cassiman, Bruno, and Reinhilde Veugelers. 2002. "R\&D Cooperation and Spillovers: Some Empirical Evidence from Belgium.” American Economic Review 92, no. 4: 1169-84. https://doi.org/10.1257/00028280260344704.

Cassiolato, José Eduardo, Jorge Britto, and M. A. Vargas. 2005. “Arranjos Cooperativos e Inovação Na Indústria Brasileira." In Inovações, Padrões Tecnológicos e Desempenho Das Firmas Industriais Brasileiras, edited by J. A. De Negri and M. S. Salerno, 511-76. Brasília: IPEA. 
Cassiolato, José Eduardo, Marcelo Pessoa de Matos, and Helena M M Lastres. 2014. Empresas Transnacionais e o Desenvolvimento Tecnológico Brasileiro. Edited by José Eduardo Cassiolato, Marcelo Pessoa de Matos, and Helena M. M. Lastres. Desenvolvimento e Mundialização: O Brasil e o Pensamento de Fançois Chesnais. Rio de Janeiro: E-Papers. https://doi.org/10.13140/2.1.2272.6404.

Cohen, Wesley M, and Daniel A Levinthal. 1990. “Absorptive Capacity: A New Perspective on Learning and Innovation.” Administrative Science Quarterly 35, no. 1: 128-52.

Consoni, Flávia. 2004. "Da Tropicalização Ao Projeto de Veículos: Um Estudo Das Competências Em Desenvolvimento de Produtos Nas Montadoras de Automóveis No Brasil.” 267 p. Tese (Doutorado) - Instituto de Geociências. Universidade Estadual de Campinas.

Dunning, John H. 1994. "Multinational Enterprises and the Globalization of Innovatory Capacity." Research Policy 23, no. 1: 67-88. https://doi.org/0048-7333(94)90027-2.

Erber, Fabio Stefano. 2010. "Inovação Tecnológica Na Indústria Brasileira No Passado Recente: Uma Resenha Da Literatura Econômica." Textos Para Discussão CEPAL-IPEA, no. 17: 1-84.

Falk, Martin. 2008. "Effects of Foreign Ownership on Innovation Activities: Empirical Evidence for Twelve European Countries." National Institute Economic Review 204, no. 1: 85-97. https://doi.org/10.1177/0027950108093762.

Faria, Pedro de, Francisco Lima, and Rui Santos. 2010. “Cooperation in Innovation Activities: The Importance of Partners.” Research Policy 39, no. 8 (October): 1082-92. https://doi.org/10.1016/j.respol.2010.05.003.

Fernandes, Ana C A, B. Campello De Souza, A. Stamford Da Silva, Wilson Suzigan, Catari V Chaves, and Eduardo Da Motta E Albuquerque. 2010. "Academy-Industry Links in Brazil: Evidence about Channels and Benefits for Firms and Researchers.” Science and Public Policy 37, no. 7: 485-98. https://doi.org/10.3152/030234210X512016.

Furtado, André Tosi, and Ruy de Quadros Carvalho. 2005. "Padrões de Intensidade Tecnológica Da Indústria Brasileira: Um Estudo Comparativo Com Os Países Centrais." São Paulo Em Perspectiva 19, no. 1: 70-84.

Gereffi, Gary, John Humphrey, and Timothy Sturgeon. 2005. "The Governance of Global Value Chains." Review of International Political Economy 12, no. 1 (February): 78-104. https://doi.org/10.1080/09692290500049805.

Gomes, Rogério. 2003. "O Papel Das Subsidiárias e a Internacionalização Das Atividades Tecnológicas Pelas Empresas Transnacionais." Gestão \& Produção 10, no. 3: 267-81. https://doi.org/10.1590/s0104$-530 \times 2003000300004$.

Granovetter, Mark S. 1973. "The Strength of Weak Ties.” American Journal of Sociology 78, no. 6: 1360-80.

Guadalupe, Maria, Olga Kuzmina, and Catherine Thomas. 2012. "Innovation and Foreign Ownership." American Economic Review 102, no. 7 (December): 3594-3627. https://doi.org/10.1257/aer.102.7.3594.

Hatzichronoglou, Thomas. 1997. "Revision of the High-Technology Sector and Product Classification." OECD Science, Technology and Industry Working Papers 1997/02: 26. https://doi.org/http://dx.doi. org/10.1787/134337307632.

IBGE. 2016. Pesquisa de Inovação 2014. Rio de Janeiro: IBGE.

IBGE. 2004. Pesquisa Industrial de Inovação Tecnológica - Série Relatórios Metodológicos. Edited by Instito Brasileiro de Geografia e Estatística. 30th ed. Rio de Janeiro: IBGE.

IBGE. 2004. Pesquisa Industrial de Inovação Tecnológica 2003. Rio de Janeiro: IBGE.

Kannebley Jr, Sérgio, Geciane S. Porto, and Elaine Toldo Pazello. 2004.“Inovação Na Indústria Brasileira: Uma Análise Exploratória a Partir Da Pintec.” Revista Brasileira de Inovação 3, no. 1: 87-128.

Klevorick, Alvin K, Richard C Levin, Richard R Nelson, and Sidney G Winter. 1995. "On the Sources and Significance of Interindustry Differences in Technological Opportunities.” Research Policy 24, no. 2 (March): 185-205. https://doi.org/10.1016/0048-7333(93)00762-I.

Kline, Stephen J., and Nathan Rosenberg. 1986. “An Overview of Innovation.” In The Positive Sum Strategy, edited by R. Landau and N. Rosenberg, 275-305. Washington: National Academy of Press. https://doi. org/10.1108/14601069810368485. 
Koeller, Priscila. 2018. "Dinâmica Da Inovação: Brasil Frente Aos Países Da União Europeia (Indícios de 2014)." Texto Para Discussão IPEA, no. 2371.

Levin, Richard C, Alvin K Klevorick, Richard R Nelson, and Sidney G Winter. 1987. “Appropriating the Returns from and Industrial Research and Development." Brookings Papers on Economic Activity 3, no. Special Issue on Microeconomics, 783-831.

Lundvall, Bengt-Åke. 1992. National Systems of Innovation: Towards a Theory of Innovation and Interactive Learning. London: Pinter.

Morceiro, Paulo César. 2018. "Evolution and Sectoral Competiveness of the Brazilian Manufacturing Industry." In The Oxford Handbook of the Brazilian Economy, edited by Edmund Amann, Carlos Roberto Azzoni, and Werner Baer. New York: Oxford University Press.

OECD. 2017. OECD Science, Technology and Industry Scoreboard 2017: The Digital Transformation. Paris: OECD Publishing.

Pavitt, Keith. 1984. "Sectoral Patterns of Technical Change: Towards a Taxonomy and a Theory." Research Policy 13: 343-73. https://doi.org/0048-73333/84.

Pearce, Robert D. 1999. "Decentralised R\&D and Strategic Competitiveness: Globalised Approaches to Generation and Use of Technology in Multinational Enterprises." Research Policy 28, no. 2-3: 157-78. https://doi. org/10.1016/S0048-7333(98)00115-2.

Pinho, Marcelo. 2011. “A Visão Das Empresas Sobre as Relações Entre Universidade e Empresa No Brasil: Uma Análise Baseada Nas Categorias de Intensidade Tecnológica 1.” Revista de Economia 37, no. especial: 279-306.

Powell, Walter W. 1990. "Neither Market nor Hierarchy: Network Forms of Organization.” Research in Organizational Behavior 12, no. Jan: 295-336. https://doi.org/10.4324/9780429494468-61.

Queiroz, Sérgio, and Ruy de Quadros Carvalho. 2005. "Empresas Multinacionais e Inovação Tecnológica No Brasil.” São Paulo Em Perspectiva 19, no. 2: 51-59. https://doi.org/10.1590/S0102-88392005000200005.

Rama, Ruth. 2008. "Foreign Investment Innovation: A Review of Selected Policies." The Journal of Technology Transfer 33, no. 4: 353-63. https://doi.org/10.1007/s10961-007-9050-2.

Rapini, Marcia Siqueira. 2007. "Interação Universidade-Empresa No Brasil: Evidências Do Diretório Dos Grupos de Pesquisa Do CNPq.” Estudos Econômicos 37, no. 1: 211-33. https://doi.org/10.1590/S141598482007000100004 .

Suzigan, Wilson, Eduardo Da Motta E Albuquerque, Renato Garcia, and Marcia Siqueira Rapini. 2009. "University and Industry Linkages in Brazil: Some Preliminary and Descriptive Results." Seoul Journal of Economics 22, no. 4: 591-611. https://doi.org/http://www.sje.ac.kr.

Teece, David J. 1998. "Capturing Value from Knowledge Assets: The New Economy, Markets for Know-How, and Intagible Assets." California Management Review 40, no. 3: 55-79.

Tessarin, Milene Simone. 2018. “O Papel Da Inovação, Diversificação e Vizinhança Setorial No Desenvolvimento Industrial Recente Do Brasil.” 180 p. Tese (Doutorado) - Faculdade de Economia, Administração e Contabilidade, Universidade de São Paulo, São Paulo.

Tether, Bruce S. 2002. "Who Co-Operates for Innovation, and Why." Research Policy 31, no. 6 (August): 947-67. https://doi.org/10.1016/S0048-7333(01)00172-X.

Veugelers, Reinhilde. 1997. "Internal R\&D Expenditures and External Technology Scouting." Research Policy 26: 303-15. https://doi.org/10.1016/S0048-7333(97)00019-X.

Zucoloto, Graziela F, and José Eduardo Cassiolato. 2012. "Desenvolvimento Tecnológico Por Origem de Capital: A Experiência Brasileira Recente.” Revista Brasileira de Inovação 12, no. 1: 133-70.

Zucoloto, Graziela F, and Rudinei Toneto Jr. 2005. "Esforço Tecnológico Da Indústria de Transformação Brasileira: Uma Comparação Com Países Selecionados." Revista de Economia Contemporânea 9, no. 2: 337-65.

Zuniga, Pluvia, Fernanda De Negri, Mark A. Dutz, Dirk Pilat, and André Rauen. 2016. “Conditions for Innovation in Brazil: A Review of Key Issues and Policy Challenges." IPEA Discussion Paper, no. 218: 1-102. 